
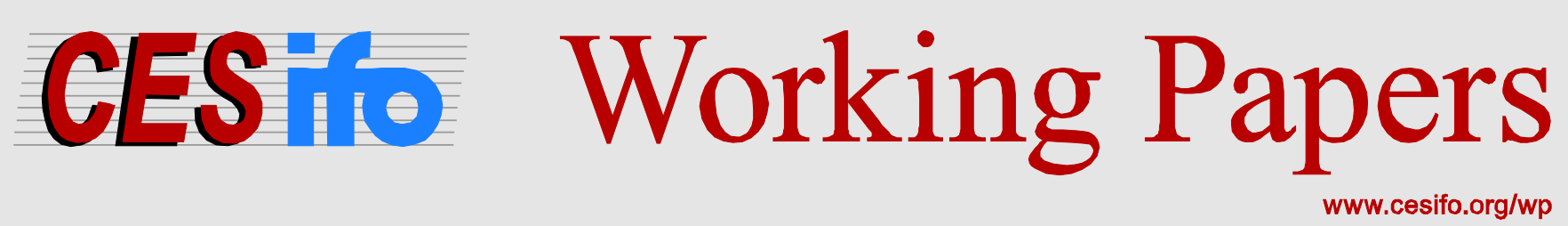

\title{
Quality and Gravity in International Trade
}

\author{
Lisandra Flach \\ Florian Unger
}

\section{CESIFO WORKING PAPER NO. 6080 \\ Category 8: TRAde Policy \\ SEPTEMBER 2016}

Presented at CESifo Area Conference on Global Economy, May 2016

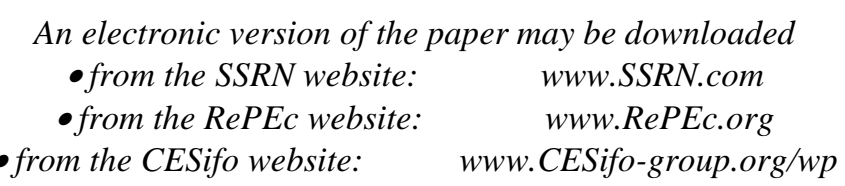




\title{
Quality and Gravity in International Trade
}

\begin{abstract}
This paper introduces quality innovations with endogenous sunk costs in a heterogeneous firm model of international trade and derives implications for the gravity equation. The model predicts that the effect of fixed costs on exports and on the share of exporters is lower in industries with a higher degree of vertical product differentiation. We use both aggregate trade data and firm-level data to estimate gravity equations and find strong evidence for a dampening effect of vertical differentiation on the fixed costs elasticity in international trade. Moreover, we estimate the parameters of our model and simulate the effects of a reduction in fixed trade barriers. Accounting for quality lowers the positive gains from trade and leads to more heterogeneous effects across industries compared to a trade model without quality investments. Consistent with our theory, vertical differentiation affects exports via sunk costs and the extensive margin, whereas the effect of variable trade costs does not depend on quality.
\end{abstract}

JEL-Codes: F120, F140, L110.

Keywords: international trade, heterogeneous firms, gravity, product quality.

\author{
Lisandra Flach \\ Department of Economics \\ University of Munich \\ Germany-80539 Munich \\ lisandra.flach@econ.Imu.de
}

\author{
Florian Unger \\ Department of Economics \\ University of Munich \\ Germany - 80539 Munich \\ florian.unger@econ.Imu.de
}

September 2, 2016

We are grateful to Daniel Baumgarten, Banu Demir, Swati Dhingra, Carsten Eckel, Julian di Giovanni, Sebastian Krautheim, Giordano Mion, Eduardo Morales, Georg Schaur, Tim Schmidt-Eisenlohr, Monika Schnitzer, Martin Watzinger, as well as participants of the Warsaw International Economic Meeting 2016, CESifo Area Conference on Global Economy 2016 in Munich, University of Vienna and FIW Workshop "International Economics" 2016, 18th Workshop "Internationale Wirtschaftsbeziehungen" in Göttingen, and of the "IO and Trade Seminar" in Munich for helpful comments and suggestions. Financial support from the Deutsche Forschungsgemeinschaft through SFB/TR15 is gratefully acknowledged. 


\section{Introduction}

Product quality is an important determinant of competitiveness in international trade. Firmlevel studies document that vertical product differentiation is crucial to explain export participation and success in foreign markets. The most successful exporters offer high-quality products with higher prices, are larger as well as more productive, and earn greater sales compared to non-exporters (Kugler and Verhoogen, 2012; Manova and Zhang, 2012). Across destinations, high-quality exporters can more easily overcome distance-related trade barriers or additional trade costs, which explains the positive correlation between distance and export prices (Baldwin and Harrigan, 2011; Manova and Zhang, 2012). This evidence at the firm- and product-level suggests that vertical differentiation affects firm sorting across destinations. In fact, two recent papers provide empirical support in this direction. Martin and Mayneris (2015) show that distance has almost no effect on French exports of high-end varieties such as luxury products. For Swedish firm-level data, Ferguson (2012) finds that the share of exporting firms is less sensitive to distance in $R \& D$ intensive industries. Whereas these studies focus on the role of vertical differentiation at the firm- or product-level, the implications for aggregate exports have received less attention.

This paper aims to fill this gap by analyzing the impact of quality innovation on firm exports and the implications for the gravity equation of international trade. We show both theoretically and empirically that the effect of fixed costs on exports and on the share of exporters is lower in industries with a higher degree of vertical product differentiation. While the literature has mainly focused on demand side explanations for quality differentiation, we highlight a new mechanism driven by firms' quality choice on the supply side. The contribution of this paper is threefold. First, we introduce quality innovations with endogenous sunk costs in a multi-country heterogeneous firm model and derive the gravity equation of international trade. Second, we use aggregate trade data and firm-level data to estimate gravity equations. The empirical analysis confirms the predictions of the theoretical model by showing that the effect is driven by the extensive margin, whereas the impact of variable trade costs does not depend on quality. Third, we estimate the parameters of our model from the data and simulate the effects of a reduction in fixed costs. Compared to a heterogeneous firm model without quality investments, gains from trade liberalization are by $14 \%$ lower on average, but become substantially more heterogeneous across industries.

This new effect of vertical differentiation on the fixed costs elasticity is based on the interaction of endogenous sunk costs as in Sutton (2007) and firm heterogeneity à la Melitz (2003). To gain some intuition, suppose that firms are heterogeneous in productivity and decide on the level of product quality as well as on which markets to serve. Quality investments increase 
demand for a particular variety, but are associated with endogenous sunk costs. Consistent with the existing literature (e.g. Crozet et al. (2012), Baldwin and Harrigan (2011)), our setup reflects quality sorting of firms. More productive firms generate larger sales and thus have higher incentives to pay additional sunk costs for quality investments. Now consider two industries that differ in their degree of vertical differentiation. In an industry with high degree of product differentiation, returns from investments and thus incentives to innovate are high, especially for the most productive firms. In this industry, high productivity firms invest relatively more in product quality and reap large market shares compared to low productivity producers. Now suppose that fixed trade barriers decrease which induces low productivity firms to enter foreign markets. In an industry with high vertical differentiation, these entrants are relatively small as they face strong competition and can only reap a tiny market share compared to existing suppliers. Hence, the effect on the extensive margin and export flows is reduced compared to an industry with lower degree of vertical differentiation. Crucially, we show that the effect of vertical differentiation on the fixed costs elasticity is opposed to the impact of horizontal differentiation as discussed in Chaney (2008). A high degree of horizontal differentiation leads to stronger effects of trade liberalization on the extensive margin as new entrants can reap larger market shares, whereas stronger quality differentiation reduces the fixed costs elasticity. Our theoretical setup allows to divide the elasticity in the gravity equation into a "Chaney (2008) - component" and a new counteracting quality effect that depends on the industrial degree of vertical differentiation. This measure reflects the firm's investments relative to sales and is determined by exogenous technology parameters in the theoretical model. A higher degree of vertical differentiation is associated with higher returns from investment.

In the empirical section, we use two proxies for quality differentiation that are closely related to the theoretical measure: (i) the "quality ladder"suggested by Khandelwal (2010), and (ii) the R\&D intensity of the industry along with the Gollop Monahan index, as used by Kugler and Verhoogen (2012). We interact these proxies with measures of fixed trade costs to estimate the effect on the gravity equation and on the extensive margin. As proxies for fixed costs, we use common language, bilateral distance controlling for variable trade costs, and administrative barriers to trade. ${ }^{1}$ Consistent with the predictions from the theoretical model, our results show that vertical differentiation affects the fixed costs elasticity of trade, both at the aggregate level and at the extensive margin. On the other hand, the effect of variable

\footnotetext{
${ }^{1}$ Bilateral distance has the advantage of being a truly exogenous measure but it also reflects variable trade costs, even though we control for tariffs and additive trade costs as in Irarrazabal et al. (2015). To minimize concerns with the distance measure, we also show that our results remain robust to the use of further proxies for fixed costs, such as common language and administrative trade barriers related to documentary compliance and border compliance.
} 
costs does not depend on quality, as predicted by our model. The results remain robust to various empirical specifications. We show that income and product weight are important to explain the empirical patterns for quality, but that our results for fixed costs remain stable and significant when we control for income factors associated with the Alchian-Allen and home market effects. The results are also robust controlling for horizontal differentiation and further confounding factors, as reported in the robustness checks.

Finally, we conduct a quantitative analysis, which suggests that vertical differentiation is an important determinant for the evaluation of liberalization policies in international trade. By taking industry-variation of quality into account, the gains from trade are reduced and become much more heterogeneous across industries compared to a benchmark scenario without vertical product differentiation.

Related literature This paper is related to two strands of literature in international trade. First, we build on theoretical and empirical work that derives and estimates gravity equations for bilateral trade. Second, this paper is based on a growing literature that emphasizes the important role of quality differentiation.

Our theoretical model combines firm heterogeneity à la Melitz (2003) and quality innovations with endogenous sunk costs similar to Sutton (2007, 2012), as well as Kugler and Verhoogen (2012). Consistent with empirical evidence on quality differentiation in international trade, our model captures that (i) firm size and prices are positively correlated (Kugler and Verhoogen, 2012), (ii) that high quality firms select into more distant markets (Baldwin and Harrigan, 2011; Crozet et al., 2012; Manova and Zhang, 2012), (iii) and that exporters vary product quality across destinations depending on distance and market characteristics (Verhoogen, 2008; Bastos and Silva, 2010; Martin, 2012; Manova and Zhang, 2012; Flach, 2016). These empirical regularities are captured in other heterogeneous firm models that allow for quality as well (Baldwin and Harrigan, 2011; Johnson, 2012; Antoniades, 2015). Related to this, Faber (2014) builds on a theoretical setup based on Kugler and Verhoogen (2012) and shows that cheaper access to US imports leads to quality upgrading and reduces the relative price of higher quality products for Mexican store data. Breinlich et al. (2016) investigate the welfare effects of the trade agreements implemented by the European Union and find that these agreements increased welfare primarily by raising the quality of the imported products. Whereas these papers focus on firm- or product-level effects, we show that firms' quality choice with endogenous sunk costs reduces the elasticity with respect to fixed costs in the gravity equation. This new quality channel is related to endogenous investments and would not appear in a framework with technology choice as in Bustos (2011). ${ }^{2}$

\footnotetext{
${ }^{2}$ In Bustos (2011), firms face a binary choice between low and high technology, which does not change
} 
We build on an international trade model with firm heterogeneity and derive gravity equations as in Chaney (2008) and Melitz and Redding (2014). We show that vertical differentiation reduces the distance effect on exports and the share of exporting firms compared to Chaney (2008). Our empirical strategy is related to Crozet and Koenig (2010) who estimate the model of Chaney (2008) for French firm-level export data. Whereas this paper does not take into account quality at the product level, two other studies are consistent with our result that vertical differentiation reduces the effect of fixed trade barriers. Martin and Mayneris (2015) use French customs data combined with a classification of high-end varieties and provide empirical evidence that distance has almost no effect on exports for these products. Ferguson (2012) shows, both theoretically and empirically for Swedish firm-level data, that $R \& D$ intense industries are less sensitive to trade costs. Whereas the focus of these papers is on highly disaggregated data from one country, we (i) analyze the implications for trade flows at the extensive and intensive margin, using both firm-level data and aggregate world trade data to evaluate the implications for the gravity equation, and (ii) we provide a theoretical model that explains these empirical patterns.

On the intersection between product quality and gravity equations at the aggregate level, Hallak (2010) provides support to the Linder (1961) hypothesis, showing in a sector by sector analysis that countries more similar in income trade more with each other. Our paper is also more generally related to the literature on product quality in international trade. Fajgelbaum et al. (2011) develop a general equilibrium model with non-homothetic preferences that offers a demand-based explanation for trade in goods of different quality. In their model, aggregate demand leads to trade specialization via home-market effects, reminiscent of a Linder (1961) hypothesis. Also using non-homothetic preferences, Feenstra and Romalis (2014) add a supply side mechanism to the demand side explanation, which gives rise to Alchian and Allen effects (Alchian and Allen, 1964). They show that firm's quality choice leads to a positive relation between distance and quality. Whereas they focus on the estimation of quality-adjusted prices, we exploit industry variation of vertical differentiation to derive the implications for the gravity equation. In our empirical analysis, we show that demand-side effects play an important role, whereas our supply-side mechanism related to sunk costs remains robust. ${ }^{3}$

The paper is structured as follows. Section 2 presents the theoretical model and derives

the fixed costs elasticity. In our model, the crucial mechanism is that endogeneous sunk costs influence firm sorting and exports.

${ }^{3}$ Feenstra and Romalis (2014) assume that quality production requires a composite input following a Cobb-Douglas function. Furthermore, fixed costs depend on productivity-adjusted wages, real expenditures in the destination market, and bilateral variables. In our model, firms pay additional sunk costs to increase the quality level, whereas technology parameters at the industry-level determine investment conditions and thus the degree of vertical differentiation. 
predictions for the empirical analysis. Section 3 describes the data, and section 4 presents the empirical analysis. In section 5, we estimate the parameters of our model and simulate the effects of a reduction in trade barriers. Finally, section 6 concludes.

\section{The model}

This section introduces quality innovations associated with endogenous sunk costs as in Sutton (2012) in a heterogeneous firm model of international trade à la Melitz (2003). We derive the gravity equation and show that endogenous investments reduce the fixed costs elasticity of trade flows, especially in industries with a high degree of vertical differentiation.

\subsection{Demand side}

The world economy consists of $N$ countries indexed by $i \in N$. A representative consumer in one country derives utility from the consumption of a homogenous good $j=0$, and a continuum of differentiated varieties in industries with $j \geq 1$. The upper-tier utility follows a Cobb-Douglas function with expenditure shares by industry $\beta_{j}$ :

$$
U=\sum_{j=0}^{J} \beta_{j} \log X_{j}, \sum_{j=0}^{J} \beta_{j}=1, \beta_{j} \geq 0
$$

Preferences for differentiated goods in industry $j$ follow a CES utility function:

$$
X_{j}=\left[\int_{\omega \in \Omega_{j}}\left(q_{j}(\omega) x_{j}(\omega)\right)^{\frac{\sigma_{j}-1}{\sigma_{j}}} d \omega\right]^{\frac{\sigma_{j}}{\sigma_{j}-1}}, \sigma_{j}>1, j \geq 1
$$

whereas individual varieties are indexed by $\omega \in \Omega_{j}$, and $\sigma_{j}$ denotes the constant elasticity of substitution. Due to the upper-tier Cobb-Douglas utility function, consumers spend $Y_{j}=$ $\beta_{j} Y$ on goods produced by industry $j$, whereas $Y$ is total income. Demand for one variety $x_{j}(\omega)$ depends negatively on the price $p_{j}(\omega)$ and positively on the quality level $q_{j}(\omega)$ :

$$
x_{j}(\omega)=A_{j} q_{j}(\omega)^{\sigma_{j}-1} p_{j}(\omega)^{-\sigma_{j}}, A_{j}=Y_{j} P_{j}^{\sigma_{j}-1} .
$$

The quality-adjusted aggregate price index in one industry $j$ is defined as:

$$
P_{j}=\left[\int_{\omega \in \Omega_{j}}\left(\frac{p_{j}(\omega)}{q_{j}(\omega)}\right)^{1-\sigma_{j}} d i\right]^{\frac{1}{1-\sigma_{j}}}
$$




\subsection{Production and quality investment}

Each country is endowed with inelastic labor $\bar{L}_{i}$ which is mobile across industries, but immobile across countries. As in Melitz (2003), a firm offers one differentiated variety $i$ in a monopolistically competitive industry. At the entry stage, each producer draws a productivity parameter $\varphi_{i}$ from a common probability distribution $g(\varphi)$. After successful entry, a firm sets the price for the good, and additionally chooses the optimal level of investment in quality $q_{j}(\omega)$. As equation (3) shows, these innovations increase the demand at any given price. We follow Kugler and Verhoogen (2012) as well as Sutton (2012) and assume that quality investments are associated with endogenous sunk costs:

$$
f\left[q_{j}(\omega)\right]=\frac{q_{j}(\omega)^{\alpha_{j}}}{\alpha_{j}} \text { with } \alpha_{j}>\sigma_{j}-1 .
$$

The technology parameter $\alpha_{j}$ is industry-specific and determines the convexity of the investment cost function. We assume that investment costs are sufficiently convex $\left(\alpha_{j}>\sigma_{j}-1\right)$ to ensure a well-defined optimum. ${ }^{4}$ Production is associated with fixed costs $f_{j}$ and variable costs such that the labor requirement of a single firm can be written as:

$$
l_{j}(\omega)=f_{j}+\frac{q_{j}(\omega)^{\theta_{j}}}{\varphi} x_{j}(\omega) \text { with } 0<\theta_{j}<1 .
$$

As in Melitz (2003), marginal production costs decrease in firm productivity $\varphi$. Additionally, a higher quality level leads to an increase in marginal production costs, whereas the parameter $\theta_{j}$ captures the elasticity of marginal costs with respect to quality. This assumption can be motivated by additional marketing or advertising expenditures and implies that higher quality is associated with higher prices. ${ }^{5}$

We assume that exporting from country $i$ to destination $n$ involves iceberg-transportation $\operatorname{costs} \tau_{n i} \geq 1$, whereas $\tau_{i i}=1$, and fixed trade $\operatorname{costs} f_{n i}>0$. Firms maximize total profits to choose the optimal price $p_{n i j}$, as well as the optimal level of product quality $q_{n i j}$ :

$$
\pi_{i j}=\sum_{n=1}^{N} \pi_{n i j}=\sum_{n=1}^{N} 1_{\left\{x_{n i j}>0\right\}}\left[s_{n i j}-\tau_{n i} \frac{q_{n i j} \theta_{j}}{\varphi} x_{n i j}-\frac{1}{\alpha_{j}} q_{n i j}^{\alpha_{j}}-f_{n i}\right],
$$

whereas the indicator $1_{\left\{x_{n i j}>0\right\}}$ takes a value of one if a firm in industry $j$ sells its product from country $i$ to destination $n$, and sales are defined as: $s_{n i j}=p_{n i j} x_{n i j}$. Equation (7)

\footnotetext{
${ }^{4}$ In particular, this convexity assumption is a sufficient condition to ensure that profits in equation (11) are well-defined and positive.

${ }^{5}$ Baldwin and Harrigan (2011) and Kugler and Verhoogen (2012) show that this assumption is crucial to explain the positive correlation of prices with distance and firm size.
} 
implies that firms separately choose prices and product quality for each destination. Hence, we abstract from investment or price interdependencies across markets. This assumption is consistent with empirical evidence that points to quality-based market segmentation of exporters (Bastos and Silva, 2010; Manova and Zhang, 2012; Flach, 2016). Solving the maximization problem yields the optimal price of a firm in industry $j$ that sells from country $i$ to destination $n: 6$

$$
p_{n i j}(\varphi)=\frac{\sigma_{j}}{\sigma_{j}-1} \frac{\tau_{n i} q_{n i j}^{\theta_{j}}}{\varphi} .
$$

The price is set as a constant markup over marginal production costs that decrease in firm productivity $\varphi$, but increase in the level of quality innovation which is given by:

$$
q_{n i j}=\left[\left(1-\theta_{j}\right) A_{n j}\left(\frac{\sigma_{j}}{\sigma_{j}-1}\right)^{-\sigma_{j}}\left(\frac{\tau_{n i}}{\varphi}\right)^{1-\sigma_{j}}\right]^{\overline{\alpha_{j}-\left(\sigma_{j}-1\right)\left(1-\theta_{j}\right)}}
$$

The quality level depends positively on the market size $A_{n j}$ and negatively on iceberg transportation $\operatorname{costs} \tau_{n i}{ }^{7}$ Firms with higher productivity have a larger incentive to invest in quality as they realize larger sales and thus face a higher return from innovations. Using equations (8) and (9), firm sales and profits from selling to a particular destination can be written as:

$$
\begin{gathered}
s_{n i j}(\varphi)=A_{n j}^{\frac{\alpha_{j}}{\alpha_{j}-\left(\sigma_{j}-1\right)\left(1-\theta_{j}\right)}}\left[\left(1-\theta_{j}\right)^{1-\theta_{j}}\left(\frac{\sigma_{j}}{\sigma_{j}-1}\right)^{\theta_{j}-1-\alpha_{j}}\left(\frac{\tau_{n i}}{\varphi}\right)^{-\alpha_{j}}\right]^{\frac{\sigma_{j}-1}{\alpha_{j}-\left(\sigma_{j}-1\right)\left(1-\theta_{j}\right)}}, \\
\pi_{n i j}=s_{n i j}(\varphi) \frac{\alpha_{j}-\left(1-\theta_{j}\right)\left(\sigma_{j}-1\right)}{\alpha_{j} \sigma_{j}}-f_{n i} .
\end{gathered}
$$

Selection of firms into exporting is determined by a zero-profit condition: $\pi_{n i j}\left(\varphi_{n i j}^{*}\right)=0$. All producers from country $i$ and industry $j$ with $\varphi>\varphi_{n i j}^{*}$ serve the foreign market $n$. By using equation (11), the zero-profit condition can be written as:

$$
s_{n i j}\left(\varphi_{n i j}^{*}\right)=\frac{\alpha_{j} \sigma_{j} f_{n i}}{\alpha_{j}-\left(1-\theta_{j}\right)\left(\sigma_{j}-1\right)},
$$

\footnotetext{
${ }^{6}$ See Appendix A.1 for a derivation of firm's maximization problem.

${ }^{7}$ In the model, $\tau_{n i}$ does not vary across industries, but it could be easily extended to industry-specific $\tau_{n i j}$, as we use in the empirical analysis.
} 
which leads to the following cutoff productivity for serving market $n$ :

$$
\varphi_{n i j}^{*}=\Delta \tau_{n i}\left(\frac{\alpha_{j} \sigma_{j} f_{n i}}{\alpha_{j}-\left(1-\theta_{j}\right)\left(\sigma_{j}-1\right)}\right)^{\frac{\alpha_{j}-\left(\sigma_{j}-1\right)\left(1-\theta_{j}\right)}{\alpha_{j}\left(\sigma_{j}-1\right)}} A_{n j}^{\frac{-1}{\sigma_{j}-1}}
$$

whereas $\Delta=\left(1-\theta_{j}\right)^{-\frac{\left(1-\theta_{j}\right)}{\alpha_{j}}}\left(\frac{\sigma_{j}}{\sigma_{j}-1}\right)^{\frac{\alpha_{j}+1-\theta_{j}}{\alpha_{j}}}$. At the entry stage, firms pay fixed entry costs $f_{E i}$ and draw their productivity parameter $\varphi$. Free entry ensures that expected profits equal the fixed entry costs $f_{E i}$ :

$$
\sum_{n=1}^{N} \int_{\varphi_{n i j}^{*}}^{\infty} \pi_{n i j}(\varphi) g_{i}(\varphi)=f_{E i}
$$

The combination of the zero-profit conditions (13) and the free-entry condition (14) uniquely pins down the entry cutoff productivity for serving the domestic market: 8

$$
\left(\varphi_{i i j}^{*}\right)^{\xi_{j}}=\frac{\alpha_{j}\left(\sigma_{j}-1\right) \sum_{n} \frac{f_{n i}}{f_{E i}} \tau_{n i}^{-\xi_{j}}\left(\frac{f_{n i}}{f_{i i}}\right)^{-\frac{\xi_{j}\left[\alpha_{j}-\left(\sigma_{j}-1\right)\left(1-\theta_{j}\right)\right]}{\alpha_{j}\left(\sigma_{j}-1\right)}}}{\xi_{j}\left[\alpha_{j}-\left(\sigma_{j}-1\right)\left(1-\theta_{j}\right)\right]-\alpha_{j}\left(\sigma_{j}-1\right)} .
$$

We use this model with quality differentiation to derive gravity equations of international trade and show that firms' investment behavior influences the elasticity of exports with respect to fixed costs. Before we do so, the next section discusses how vertical differentiation affects the competition of heterogeneous producers, which will be crucial for subsequent gravity analysis.

\subsection{The role of vertical differentiation}

The competitiveness of a firm depends on its quality-price ratio, which follows immediately from combining equations (8) and (9), and reflects how attractive a variety is for consumers:

$$
\frac{q_{n i j}}{p_{n i j}}=\left[\left(1-\theta_{j}\right)^{1-\theta_{j}} A_{n j}^{1-\theta_{j}}\left(\frac{\sigma_{j}-1}{\sigma_{j}}\right)^{\alpha_{j}+1-\theta_{j}}\left(\frac{\varphi}{\tau_{n i}}\right)^{\alpha_{j}}\right]^{\frac{1}{\alpha_{j}-\left(\sigma_{j}-1\right)\left(1-\theta_{j}\right)}} .
$$

The price-adjusted quality increases in firm productivity $\varphi$ and the market size $A_{n j}$ due to higher returns from investments. To compare the competitiveness of different producers, we consider the sales of a firm with productivity $\varphi$ relative to the least productive firm that

\footnotetext{
${ }^{8}$ See Appendix A.2 for a detailed derivation of the entry cutoff productivity.
} 
sells from the same industry $j$ and country $i$ to destination $n$ :

$$
\frac{s_{n i j}(\varphi)}{s_{n i j}\left(\varphi_{n i j}^{*}\right)}=\left(\frac{\varphi}{\varphi_{n i j}^{*}}\right)^{\frac{\alpha_{j}\left(\sigma_{j}-1\right)}{\alpha_{j}-\left(\sigma_{j}-1\right)\left(1-\theta_{j}\right)}}
$$

Relative sales in equation (17) depend on the productivity difference, as well as on the technology parameters $\alpha_{j}$ and $\theta_{j}$. Following Kugler and Verhoogen (2012), these technology parameters determine the $\mathrm{R} \& \mathrm{D}$ intensity in an industry $j$, defined as the ratio of expenditures for quality innovations relative to firm sales:

$$
\frac{\frac{1}{\alpha_{j}} q_{n i j}^{\alpha_{j}}(\varphi)}{s_{n i j}(\varphi)}=\frac{1-\theta_{j}}{\alpha_{j}} \frac{\sigma_{j}-1}{\sigma_{j}}
$$

In our empirical analysis, we consider industries with different degree of vertical differentiation, which is determined by the technology parameters $\alpha_{j}$ and $\theta_{j}$ in the theoretical model. If investment costs are less convex (low $\alpha_{j}$ ) or the elasticity of marginal production costs with respect to quality is low (low $\theta_{j}$ ), returns from quality innovations become larger. In such an industry, firms have high incentives to invest in quality relative to sales, which leads to a large degree of vertical differentiation (18). This high incentive to innovate holds especially for high productivity firms as they face larger sales and thus higher returns from investments. Equations (16) and (17) show that high productivity firms invest more in (price-adjusted) quality and earn relatively larger market shares compared to low productivity firms, whenever the degree of vertical differentiation is high. Thus, low productivity firms face stronger competition in industries with higher degree of vertical differentiation as it becomes more difficult for them to reap positive market shares. This impact of vertical differentiation on the competition among firms will be decisive to explain the effect of trade barriers for the gravity equation, which is derived in the following subsection.

\subsection{Gravity equation and comparative statics}

We aggregate sales $s_{n i j}(\varphi)$ of all firms that serve a particular destination, to obtain an expression for export flows from country $i$ and industry $j$ to country $n$ :

$$
S_{n i j}=\frac{1-G_{i j}\left(\varphi_{n i j}^{*}\right)}{1-G_{i j}\left(\varphi_{i i j}^{*}\right)} M_{i j} \int_{\varphi_{n i j}^{*}}^{\infty} s_{n i j}(\varphi) \frac{g_{i j}(\varphi)}{1-G_{i j}\left(\varphi_{n i j}^{*}\right)} d \varphi
$$

We assume that productivity $\varphi$ is Pareto distributed with density function $g_{i j}(\varphi)=\xi_{j} \varphi^{-\xi_{j}-1}$, whereas $\xi_{j}$ is the Pareto shape parameter and $G_{i j}(\varphi)$ is the cumulative distribution function. 
This assumption implies that the share of exporters can be expressed as follows:

$$
\gamma_{n i j}=\frac{1-G_{i j}\left(\varphi_{n i j}^{*}\right)}{1-G_{i j}\left(\varphi_{i i j}^{*}\right)}=\tau_{n i}^{-\xi_{j}}\left(\frac{f_{n i}}{f_{n n}}\right)^{-\xi_{j} \frac{\alpha_{j}-\left(\sigma_{j}-1\right)\left(1-\theta_{j}\right)}{\alpha_{j}\left(\sigma_{j}-1\right)}}
$$

and the gravity equation $(19)$ can be written as: ${ }^{9}$

$$
S_{n i j}=\underbrace{\tau_{n i}^{-\xi_{j}}\left(\frac{f_{n i}}{f_{i i}}\right)^{-\xi_{j} \frac{\alpha_{j}-\left(\sigma_{j}-1\right)\left(1-\theta_{j}\right)}{\alpha_{j}\left(\sigma_{j}-1\right)}} M_{i j}}_{\text {Extensive margin }} \underbrace{\frac{\xi_{j} \alpha_{j} \sigma_{j} f_{n i}}{\xi_{j}\left[\alpha_{j}-\left(\sigma_{j}-1\right)\left(1-\theta_{j}\right)\right]-\alpha_{j}\left(\sigma_{j}-1\right)}}_{\text {Intensive margin }} .
$$

Following Melitz and Redding (2014), total export sales can be divided into an extensive margin as well as an intensive margin component. To disentangle exporter and importer fixed effects, which will be important in the subsequent empirical analysis, we rewrite equation (21) and obtain:

$$
S_{n i j}=\frac{S_{i j}}{\Xi_{i j}}\left(\frac{Y_{n}}{P_{n}^{1-\sigma_{j}}}\right)^{\frac{\xi_{j}}{\sigma_{j}-1}} \tau_{n i}^{-\xi_{j}}\left(f_{n i}\right) \frac{\alpha_{j}\left(\sigma_{j}-1\right)-\xi_{j}\left[\alpha_{j}-\left(\sigma_{j}-1\right)\left(1-\theta_{j}\right)\right]}{\alpha_{j}\left(\sigma_{j}-1\right)}
$$

whereas $S_{i j}=\sum_{n} S_{n i j}$ denotes total sales of industry $j$ in country $i$. Exporter-industry fixed

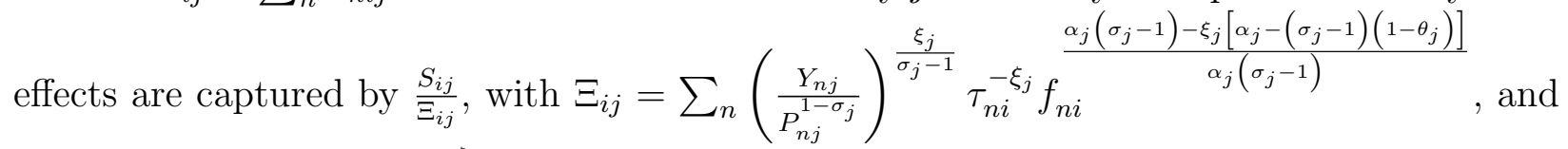
the second term $\left(\frac{Y_{n}}{P_{n}^{1-\sigma_{j}}}\right)^{\frac{\xi_{j}}{\sigma_{j}-1}}$ reflects importer fixed effects. We analyze the impact of fixed and variable trade costs on bilateral trade flows and the extensive margin of international trade. The effect of fixed trade costs on exports from country $i$ and industry $j$ to destination $n$ follows immediately from equation (22):

$$
\frac{d \ln S_{n i j}}{d \ln f_{n i}}=\underbrace{1-\frac{\xi_{j}}{\sigma_{j}-1}}_{\text {Chaney (2008) }}+\underbrace{\frac{\xi_{j}\left(1-\theta_{j}\right)}{\alpha_{j}}}_{\text {Quality effect }} .
$$

The total impact can be decomposed into two effects. The first part in equation (23) is the same elasticity as in Chaney (2008). The last term, however, is a new quality effect that would not be present in a model without vertical differentiation. For industries with lower technology parameters $\alpha_{j}$ and $\theta_{j}$ and thus a higher scope for vertical differentiation (18), the trade elasticity of export flows becomes lower.

\footnotetext{
${ }^{9}$ See Appendix A.3 for a derivation of the gravity equation (21).
} 
Prediction 1 The elasticity of trade flows with respect to fixed trade costs is lower in industries with higher scope for vertical differentiation.

This prediction is driven by adjustments at the extensive margin. To see this, the elasticity of the share of exporters with respect to fixed trade costs can be divided into a direct effect and a new quality effect as well, following from equation (20):

$$
\frac{d \ln \gamma_{n i j}}{d \ln f_{n i}}=\underbrace{-\frac{\xi_{j}}{\sigma_{j}-1}}_{\text {Chaney (2008) }}+\underbrace{\frac{\xi_{j}\left(1-\theta_{j}\right)}{\alpha_{j}}}_{\text {Quality effect }} .
$$

Prediction 2 The elasticity of the share of exporters with respect to fixed trade costs is lower in industries with higher scope for vertical differentiation.

As for export flows, the direct negative effect of fixed trade costs is reduced in industries with high scope for vertical differentiation. The intuition for this counteracting quality effect follows the discussion in subsection 2.3. A decrease in fixed trade barriers induces lower productivity firms to enter export markets. However, in an industry with a high degree of vertical differentiation, it becomes more difficult for new entrants with low productivity and thus low price-adjusted quality to reap positive market shares as they face strong competition from existing high quality firms. Hence, the effect of lower trade barriers on the extensive margin and on export flows is relatively weak in those industries. Conversely, new entrants after trade liberalization are relatively large in industries with low scope for quality differentiation. Hence, the effects at the extensive margin and on aggregate export flows are strong.

Interestingly, the effect of quality differentiation on the distance elasticities (23) and (24) is opposed to the impact of horizontal differentiation, as discussed in Chaney (2008). If the degree of horizontal differentiation is high (lower $\sigma_{j}$ ), consumers react less sensitive to price differences, such that new entrants with low productivity find it easier to reap market shares. Thus, horizontal differentiation increases the impact of fixed trade costs on the extensive margin, whereas vertical differentiation reduces the effect on trade. This implication will be important to distinguish between horizontal and vertical differentiation in the empirical analysis. As in Chaney (2008), the effect of variable trade costs on bilateral export sales and the share of exporters only depends on the Pareto shape parameter:

$$
\frac{d \ln S_{n i j}}{d \ln \tau_{n i}}=\frac{d \ln \gamma_{n i j}}{d \ln \tau_{n i}}=-\xi_{j} .
$$

Intuitively, the impact of vertical differentiation works through endogenous sunk costs and adjustments at the extensive margin. This channel is not present for variations in variable 
trade costs.

Prediction 3 Variable trade costs reduce export sales and the share of exporters. The scope for vertical product differentiation has no effect on the elasticity of trade flows with respect to variable trade costs.

\section{Data}

To investigate the main predictions from the theory, we need three main ingredients. First, we require trade data, both at the aggregate level and at the firm level. We use aggregate world bilateral trade flows from COMTRADE and NBER-UN, as well as Brazilian firm-level data from SECEX (Foreign Trade Secretariat). The COMTRADE data provides information on total exports $S_{n i j}$ from country $i$ to country $n$ in industry $j$. The firm-level data provides information on total exports $s_{n j f}$ from firm $f$ to country $n$ in industry $j$. With this information, we construct a measure for the share of exporters by destination and industry, $\gamma_{n j} \cdot{ }^{10}$

Second, we need information on the degree of quality differentiation of the industry to estimate the effect of vertical differentiation on the trade elasticity. Hence, we combine trade data with different measures of vertical differentiation. The first measure of differentiation is the "quality ladder"suggested by Khandelwal (2010), which is closely related to the degree of vertical differentiation (18) in our theoretical model. Intuitively, a higher degree of differentiation leads to more favorable investment conditions, such that firms invest more in quality and generate larger sales conditional on firm size and prices. This follows the idea of Khandelwal (2010) that quality can be inferred from the estimation of market shares after controlling for prices and country characteristics. ${ }^{11}$ Because this measure is available for a larger number of industries (see summary statistics in Table B2), we use it as the main measure of vertical differentiation. The second measure of differentiation is the R\&D intensity of the industry used by Kugler and Verhoogen (2012), which resembles the theoretical model. As shown in equation (18) in the theory, we can express the R\&D intensity in an industry $j$ as the ratio of expenditures for quality innovations relative to firm sales. Finally, we also use a proxy for horizontal differentiation based on the Gollop Monahan index, suggested by Kugler and Verhoogen (2012). ${ }^{12}$ When we use the measure of horizontal differentiation

\footnotetext{
${ }^{10}$ The firm-level data is avaiable at the 8-digit NCM classification (Nomenclatura Comum do Mercosur). The data is combined with the 4-digit SITC classification of goods and the CNAE industry classification (Classificação Nacional de Atividades Econômicas). More details are provided in the data appendix.

${ }^{11}$ See Appendix A.4 for a more formal comparison of our model to Khandelwal (2010).

${ }^{12}$ We take the values computed by Kugler and Verhoogen (2012) based on the Gollop and Monahan (1991) index. The measure exploits the dissimilarity of input mixes across plants within an industry and was
} 
along with vertical differentiation, we can directly relate the empirical results to equation (23) in the theory, where we decompose the trade elasticity into the "Chaney (2008) - component" of horizontal differentiation and our new counteracting quality effect that depends on vertical differentiation. All industry-level measures are aggregated to the 4-digit SITC classification (Standard International Trade Classification) revision 2. Besides the close relation to our theory, another advantage of the industry-level measures is that they are taken from the analysis of US data, and hence, they are less subject to endogeneity concerns in our empirical analysis.

Third, we need information on variable and fixed trade costs. We use tariffs and additive trade costs as measures for variable trade costs. Tariff data $\left(\tau_{\text {nijt }}\right)$ come from TRAINS-WTI ${ }^{13}$ and additive trade costs are estimated based on Irarrazabal et al. (2015), as shown in the robustness checks, section 4.3.5. To measure fixed trade barriers, we use different proxies, such as bilateral distance $\left(\right.$ Dist $\left._{n i}\right)$ and common language $\left(\right.$ Language $\left._{n i}\right)$ from CEPII, and measures of administrative trade barriers from the Doing Business - Trading Across Borders (World Bank, 2016). Bilateral distance might reflect both fixed and variable trade costs. However, it has the advantage of being a truly exogenous measure and of providing empirical insights that can be easily related to the previous literature (for instance, to Chaney (2008), Martin and Mayneris (2015), Crozet and Koenig (2010), and Ferguson (2012)). Hence, we use distance controlling for tariffs and additive trade costs, and provide further results using other proxies for fixed costs. The measures of administrative trade barriers from the World Bank refer to the time for documentary compliance $t_{-} d o c_{n i}$ and border compliance $t_{-} b o r d e r_{n i}$. The time for documentary compliance includes the time in hours to comply with the documentary requirements of the government agencies in the origin and destination country, including transit economies. The variable border compliance captures the time in hours to comply with the regulations relating to customs clearance and mandatory inspections to cross the border. The variables are described in more detail in the Appendix B.1. The main variables of interest are summarized in Table B2. ${ }^{14}$

originally created to measure diversification across establishments of multi-establishment firms. However, as described by Kugler and Verhoogen (2012), it also captures well horizontal differentiation across firms.

${ }^{13}$ The tariff data have the advantage of being a time-varying measure of variable costs, such that we can identify the coefficient including importer-exporter-industry fixed effects. We use the AHS tariffs (effective applied tariffs), and conduct robustness checks using MFN (Most Favored Nation) tariffs.

${ }^{14}$ For the firm-level data, there are more missing observations for the variables $t_{-} b o r d e r_{n i}$ and $t_{-} d o c_{n i}$. The main reason is the large number of observations between Brazil and countries with value zero for the compliance measures, such as Austria, Belgium, Germany, Italy, Netherlands, and Sweden. We conduct robustness checks using the $\log$ of the variable +1 for all specifications and the results remain robust. 


\section{Empirical analysis}

The objective of this section is to provide theory-consistent estimations of the trade elasticity with respect to fixed and variable costs depending on the industrial degree of vertical differentiation. We provide results for aggregate trade flows and for the extensive margin of exports in sections 4.1 and 4.2, respectively, and robustness checks in section 4.3.

\subsection{The elasticity of trade flows with respect to fixed costs: Re- sults for aggregate trade flows}

We start by investigating the first proposition from our theory, which refers to the aggregate trade elasticity with respect to fixed costs. We can write a log-linearized version of the gravity equation shown in equation (22) and obtain:

$$
\ln S_{n i j}=\ln \left(\frac{S_{i j}}{\Xi_{i j}}\right)+\ln \left(\frac{Y_{n}}{P_{n}^{1-\sigma_{j}}}\right)^{\frac{\xi_{j}}{\sigma_{j}-1}}-\xi_{j} \ln \tau_{n i}+\frac{\alpha_{j}\left(\sigma_{j}-1\right)-\xi_{j}\left[\alpha_{j}-\left(\sigma_{j}-1\right)\left(1-\theta_{j}\right)\right]}{\alpha_{j}\left(\sigma_{j}-1\right)} \ln f_{n i j}
$$

Because we are interested in the elasticity with respect to fixed costs, we hold constant origin-specific and destination-specific terms (income and price indices). Empirically, this means that we include importer-industry and exporter-industry fixed effects in the gravity regressions, which absorb the terms $\left(\frac{S_{i j}}{\Xi_{i j}}\right)$ and $\left(\frac{Y_{n}}{P_{n}^{1-\sigma_{j}}}\right)^{\frac{\xi_{j}}{\sigma_{j}-1}}$, respectively.

The effect of variable trade costs $\left(\tau_{n i}\right)$ on sales depends only on the Pareto shape parameter. We control for importer-exporter $\tau_{n i}$ in different ways: by including control variables such as standard gravity covariates, tariffs, and bilateral importer-exporter fixed effects. However, the main interest of Proposition 1 refers to the differential effects across industries depending

on the ratio $\frac{1-\theta_{j}}{\alpha_{j}}$ (the sensitivity with respect to quality). We proxy this ratio by the degree of vertical differentiation of the industry, using ladder $_{j}$ or the R\&D intensity of the industry. Hence, to investigate the effect of quality on the trade elasticity at the aggregate level, we use an interaction term between fixed costs and the degree of differentiation of the industry, as follows:

$$
\ln S_{n i j}=\beta_{1} \text { fixedcosts }_{n i}+\beta_{2} \text { fixedcosts }_{n i} * \text { ladder }_{j}+x_{n i j}+\rho_{i j}+\mu_{n j}+\varepsilon_{n i j}
$$

where $n$ is the importer, $i$ is the exporter, $j$ is the SITC 4-digit industry, $S_{n i j}$ are the export flows from country $i$ to $n$ in industry $j$, ladder $_{j}$ is the degree of differentiation of industry $j$, $\mu_{n j}$ and $\rho_{i j}$ are importer-industry and exporter-industry fixed effects, $\varepsilon_{n i j}$ is the error term, and $x_{n i j}$ are gravity covariates and further control variables such as tariffs. We also conduct the analysis including bilateral importer-exporter fixed effects $v_{n i}$. Fixed costs are proxied 
in different ways. First, we conduct the analysis using distance (controlling for tariffs as a proxy for variable trade costs), as it provides important insights closely related to the quality sorting literature (e.g. Martin and Mayneris (2015) and Crozet et al. (2012)). Second, we run regressions using further proxies of fixed costs, such as language and time for border and documentary compliance.

Higher fixed costs imply that $\beta_{1}<0$ (see the discussion in section 2.4). The new element in the estimation and main coefficient of interest is $\beta_{2}$. Proposition 1 shows that the elasticity of trade flows with respect to fixed trade costs is lower in industries with higher scope for vertical differentiation. Hence, in industries with a high ladder $_{j}$, we expect a dampening effect, such that $\beta_{2}>0$. Besides being closely related to our theoretical framework, another advantage of the empirical $l a d d e r_{j}$ measures is that they are taken from the analysis of US data and hence, they are less subject to endogeneity concerns in our empirical analysis. The baseline results for equation (26) are reported in Table 1 for distance (controlling for tariffs) and in Table 2 for further proxies for fixed costs. We report the baseline results using ladder $_{j}$ and provide robustness checks using R\&D intensity in section 6.3.

The results reported in Table 1 reveal that the level effect $\beta_{1}$ is always negative, whereas the interaction term $\beta_{2}$ is positive and significant. Since we are interested in the portion of the distance effect that is explained by fixed costs, in columns 3 and 4 we control for tariffs as a proxy for variable trade costs, and the results remain significant. Moreover, as expected, tariffs $\ln \tau_{n i j}$ have a negative and significant effect on trade flows, also when adding industryimporter, industry-exporter and importer-exporter fixed effects. Finally, in columns 5 and 6 we add an interaction term $\ln \tau_{n i j} *$ ladder $_{j}$. The interaction term reveals that quality has no effect on the trade elasticity with respect to variable costs (as expected from prediction 3 in the theory), whereas our coefficient of interest ln Dist $_{n i} * \operatorname{ladder}_{j}$ remains significant and stable. The results remain robust when we include importer-exporter fixed effects, $v_{n i}$, as shown in the even columns.

The results reported in Table 1 allow for a comparison of coefficients across columns. In the Appendix B.3, we provide robustness checks using the complete sample without tariff data, for which we lose many observations. The positive interaction of vertical differentiation with distance can also be shown by estimating industry-specific coefficients. We show the results for estimations by industry in Appendix B.2, and in Figure B1. As expected, there is a strong positive correlation between vertical differentiation and the estimated interaction term. For industries with high quality ladders, distance has a much lower impact on both export sales and the share of exporters. 
Table 1: Fixed costs and aggregate trade flows

\begin{tabular}{rcrrrrr}
\hline Dependent variable & & & & & \\
$\ln S_{n i j}$ & $(1)$ & $(2)$ & $(3)$ & $(4)$ & \multicolumn{1}{c}{$(5)$} & \multicolumn{1}{c}{$(6)$} \\
\hline & & & & & & \\
$\ln$ Dist $_{n i}$ & $-0.958^{* * *}$ & & $-0.947^{* * *}$ & & $-0.946^{* * *}$ & \\
& $(0.0284)$ & & $(0.0278)$ & & $(0.0278)$ & \\
$\ln$ Dist $_{n i} *$ ladder $_{j}$ & $0.100^{* * *}$ & $0.105^{* * *}$ & $0.0978^{* * *}$ & $0.103^{* * *}$ & $0.0958^{* * *}$ & $0.102^{* * *}$ \\
& $(0.0122)$ & $(0.0122)$ & $(0.0122)$ & $(0.0121)$ & $(0.0123)$ & $(0.0123)$ \\
$\ln \tau_{n i j}$ & & & $-1.541^{* * *}$ & $-1.388^{* * *}$ & $-1.651^{* * *}$ & $-1.425^{* * *}$ \\
& & & $(0.535)$ & $(0.232)$ & $(0.541)$ & $(0.290)$ \\
$\ln \tau_{n i j} *$ ladder $j$ & & & & & 0.221 & 0.0753 \\
& & & & & $(0.326)$ & $(0.331)$ \\
\hline Constant & yes & yes & yes & yes & yes & yes \\
$n j$ fixed effects & yes & yes & yes & yes & yes & yes \\
$i j$ fixed effects & yes & yes & yes & yes & yes & yes \\
$n i$ fixed effects & no & yes & no & yes & no & yes \\
Observations & 159,039 & 159,039 & 159,039 & 159,039 & 159,039 & 159,039 \\
R-squared & 0.656 & 0.719 & 0.657 & 0.720 & 0.657 & 0.720 \\
\hline
\end{tabular}

Notes: ${ }^{*}$ significant at $10 \%$; ${ }^{* *}$ significant at $5 \%$; ${ }^{* * *}$ significant at $1 \%$.

The errors are clustered by importer-exporter pair.

Additional measures of fixed costs One important concern with the measure of bilateral distance is that it may capture both variable and fixed trade costs. We address this concern in two ways. First, we control for tariffs as a proxy for variable trade costs and show that the interaction term of tariffs with quality is not significant, whereas the distance effect remains robust. ${ }^{15}$ Second, we investigate the sensitivity of the results to the use of $t_{-}$border $_{n i}, t_{-} d o c_{n i}$, and Language ${ }_{n i}$ as further proxies for fixed costs. The results reported in Table 2, columns 1 to 4, confirm the previous results: higher time and costs for border and documentary compliance are associated with lower trade flows, but this effect is less pronounced in high quality industries with a high $l_{a d d e r}$. Finally, columns 5 and 6 show the results for common language, Language $_{n i}$. A common language implies lower barriers and hence more trade. However, this effect is smaller in high quality industries, confirming prediction 1.

\footnotetext{
${ }^{15}$ Note that the bias in the distance measure is less severe because we include interacted importer-industry and exporter-industry fixed effects. However, also in this case, the distance measure could capture other types of variable trade costs that are specific to a country pair and product.
} 
Table 2: Fixed costs and aggregate trade flows: Alternative proxies for fixed costs Dependent variable

\begin{tabular}{|c|c|c|c|c|c|c|}
\hline $\ln S_{n i j}$ & (1) & (2) & (3) & (4) & (5) & (6) \\
\hline $\ln t_{-}$border $r_{n i}$ & $\begin{array}{c}-0.105^{* * *} \\
(0.0277)\end{array}$ & & & & & \\
\hline $\ln t_{\text {boorder }}{ }_{n i} *$ ladder $_{j}$ & $\begin{array}{c}0.00590^{* *} \\
(0.00269)\end{array}$ & $\begin{array}{c}0.0108 * * * \\
(0.00285)\end{array}$ & & & & \\
\hline $\ln t_{-} d o c_{n i}$ & & & $\begin{array}{c}-0.396^{* * *} \\
(0.0297)\end{array}$ & & & \\
\hline $\ln t_{-} d o c_{n i} * \operatorname{ladder}_{j}$ & & & $\begin{array}{c}0.00940 * * * \\
(0.00210)\end{array}$ & $\begin{array}{l}0.0157^{* * *} \\
(0.00217)\end{array}$ & & \\
\hline language $_{n i}$ & & & & & $\begin{array}{r}1.072^{* * *} \\
(0.0768)\end{array}$ & \\
\hline language $_{n i} *$ ladder $_{j}$ & & & & & $\begin{array}{r}-0.0685^{* * *} \\
(0.0112)\end{array}$ & $\begin{array}{r}-0.0745^{* * *} \\
(0.0104)\end{array}$ \\
\hline Constant & yes & yes & yes & yes & yes & yes \\
\hline$n j$ fixed effects & yes & yes & yes & yes & yes & yes \\
\hline ij fixed effects & yes & yes & yes & yes & yes & yes \\
\hline$n i$ fixed effects & no & yes & no & yes & no & yes \\
\hline Observations & 357,769 & 357,769 & 409,443 & 409,443 & 422,843 & 421,120 \\
\hline R-squared & 0.530 & 0.710 & 0.526 & 0.709 & 0.534 & 0.707 \\
\hline
\end{tabular}

Notes: ${ }^{*}$ significant at $10 \% ;{ }^{* *}$ significant at $5 \%$; ${ }^{* * *}$ significant at $1 \%$.

The errors are clustered by importer-exporter pair. 


\subsection{The elasticity of trade flows with respect to fixed costs: Re- sults for the share of exporters}

To investigate proposition 2 regarding the effect of quality through fixed costs on the share of exporters $\left(\gamma_{n i j}\right)$, we use Brazilian firm-level data. Hence, the dimension $i$ is fixed in the estimations, such that $\gamma_{n i j}$ in equation (20) is estimated only by $n$ and $j$. We estimate equation (20) as follows:

$$
\gamma_{n j}=\beta_{1} \text { fixedcosts }_{n}+\beta_{2} \text { fixedcosts }_{n} * \text { ladder }_{j}+\nu_{j}+x_{n j}+\varepsilon_{n j}
$$

where $\gamma_{n j}$ is the share of Brazilian exporters in industry $j$ and destination country $n$, defined as the number of exporters in industry $j$ exporting to destination country $n$ divided by the total number of exporters in industry $j$. The measure fixedcosts $s_{n}$ refers to the costs to export from Brazil to destination country $n$, such as the distance to country $n$ and administrative barriers related to the time and costs to import of country $n$. Gravity control variables are given by $x_{n j}$. In some specifications, we also include importer fixed effects $v_{n}$ besides industry fixed effects $\nu_{j}$.

Proposition 2 suggests that the share of exporters reacts more in industries with lower scope for differentiation. Hence, we expect that in industries with high $\operatorname{ladder}_{j}$ the effect of distance on trade is reduced, i.e. that $\beta_{2}>0$.

The first empirical evidence for equation (27) is reported in Table 3 using distance. The results reveal that the share of exporters decreases in distance, but this effect is smaller in high quality industries. The effect remains robust when including tariffs and destination country $n$ and industry $j$ fixed effects.

Also for the share of firms, we report results using alternative measures of fixed costs, $t_{-} b o r d e r_{n i}$ and $t_{-} d o c_{n i}$. The results reported in Table 4 reveal that the results remain significant. ${ }^{16}$

\footnotetext{
${ }^{16}$ Note that, for the share of exporters, we do not report the results for Language $_{n i}$. Since we only use data for Brazilian firms, common language Language $_{n i}$ does not provide enough variation to identify the effect.
} 
Table 3: Fixed costs and the share of exporters

\begin{tabular}{|c|c|c|c|c|c|c|}
\hline $\begin{array}{r}\text { ependent variable: } \\
\gamma_{n j} \\
\end{array}$ & (1) & (2) & (3) & (4) & (5) & (6) \\
\hline $\ln \operatorname{Dist}_{n}$ & $\begin{array}{r}-0.0676^{* * *} \\
(0.00398)\end{array}$ & & $\begin{array}{r}-0.0579^{* * *} \\
(0.00418)\end{array}$ & & $\begin{array}{r}-0.0574^{* * *} \\
(0.00420)\end{array}$ & \\
\hline $\ln \operatorname{Dist}_{n} *$ ladder $_{j}$ & $\begin{array}{r}0.00988^{* * *} \\
(0.00209)\end{array}$ & $\begin{array}{r}0.0105^{* * *} \\
(0.00215)\end{array}$ & $\begin{array}{r}0.00539^{* *} \\
(0.00222)\end{array}$ & $\begin{array}{r}0.00669^{* * *} \\
(0.00216)\end{array}$ & $\begin{array}{r}0.00509^{* *} \\
(0.00232)\end{array}$ & $\begin{array}{r}0.00648^{* * *} \\
(0.00224)\end{array}$ \\
\hline $\ln \tau_{n j}$ & & & $\begin{array}{r}-0.0235 \\
(0.0277)\end{array}$ & $\begin{array}{r}-0.0243 \\
(0.0277)\end{array}$ & $\begin{array}{r}0.0154 \\
(0.0202)\end{array}$ & $\begin{array}{r}-0.0143 \\
(0.0420)\end{array}$ \\
\hline $\ln \tau_{n j} * \operatorname{ladder}_{j}$ & & & & & $\begin{array}{r}-0.00435 \\
(0.0348)\end{array}$ & $\begin{array}{r}-0.00602 \\
(0.0221)\end{array}$ \\
\hline Constant & yes & yes & yes & yes & yes & yes \\
\hline$n$ fixed effects & no & yes & no & yes & no & yes \\
\hline$j$ fixed effects & yes & yes & yes & yes & yes & yes \\
\hline Observations & 60,032 & 60,032 & 30,646 & 30,646 & 30,646 & 30,646 \\
\hline R-squared & 0.472 & 0.490 & 0.553 & 0.566 & 0.553 & 0.566 \\
\hline
\end{tabular}

Notes: ${ }^{*}$ significant at $10 \% ;{ }^{* *}$ significant at $5 \% ;{ }^{* * *}$ significant at $1 \%$.

The errors are clustered by importer $n$.

Table 4: Fixed costs and the share of exporters: alternative proxies for fixed costs Dependent variable

\begin{tabular}{rcccc}
$\gamma_{n j}$ & $(1)$ & $(2)$ & $(3)$ & $(4)$ \\
\hline $\ln t_{\text {_border }}$ & $-0.0139^{* * *}$ & & & \\
& $(0.00171)$ & & & \\
$\ln$ t_border $_{n} *$ ladder $_{j}$ & $0.00647^{* *}$ & $0.00477^{*}$ & & \\
& $(0.00282)$ & $(0.00274)$ & & \\
$\ln t_{\text {_doc }} n$ & & & $-0.0296^{* * *}$ & \\
& & & $(0.00497)$ & \\
$\ln t_{\text {_doc }} *$ ladder $_{j}$ & & & $0.00967^{* * *}$ & $0.00781^{* * *}$ \\
& & & $(0.00266)$ & $(0.00277)$ \\
\hline Constant & yes & yes & yes & yes \\
$n$ fixed effects & no & yes & no & yes \\
$j$ fixed effects & yes & yes & yes & yes \\
\hline Observations & 43,802 & 43,802 & 42,647 & 42,647 \\
R-squared & 0.321 & 0.407 & 0.502 & 0.540 \\
\hline
\end{tabular}

Notes: ${ }^{*}$ significant at $10 \%$; ${ }^{* *}$ significant at $5 \%$; ${ }^{* * *}$ significant at $1 \%$.

The errors are clustered by importer $n$. 


\subsection{Robustness checks}

This section shows that our results are robust to alternative specifications and estimation strategies. Section 4.3.1 reports results for R\&D intensity as an alternative measure for vertical differentiation and takes into account horizontal differentiation. In section 4.3.2, we consider product weights and income per capita to control for Alchian-Allen effects and home market effects. Section 4.3.3 uses panel data to exploit time variation in tariffs. Furthermore, we account for zeros in trade using PPML estimation (4.3.4) and for additive trade costs (4.3.5). Finally, section 4.3.6 shows that the effect of vertical differentiation is not driven by export values per unit, as the results for export quantities lead to similar results.

\subsubsection{R\&D intensity and horizontal differentiation}

Because the measure $l^{a d d e r} r_{j}$ is available for a larger number of industries, we use it as the preferred measure of vertical differentiation. However, as shown in equation (18) in the theoretical model, quality differentiation reflects the ratio of firm investment to firm sales. Hence, in order to get closer to the theoretical mechanism, we replicate the analysis for total exports and the share of firms (predictions 1 and 2) using a measure of R\&D intensity as in Kugler and Verhoogen (2012), which reflects R\&D investments over sales.

Table 5 shows the results for the distance effect. The same results are reported for the share of firms in Table B6. The results in columns 1 and 2 confirm the baseline results: the negative effect of distance on trade is smaller in industries with higher R\&D intensity. The results remain robust when controlling for importer-exporter fixed effects.

However, R\&D intensity does not necessarily mean vertical differentiation. Hence, we follow Kugler and Verhoogen (2012) and control for horizontal differentiation in the regressions using the Gollop Monahan (GM) index as a proxy for horizontal differentiation. The advantage of this approach is that we can relate the empirical results to equation (23) in the theory, where we decompose the trade elasticity into the "Chaney (2008) - component"that depends on horizontal differentiation and our new counteracting quality effect that is also influenced by vertical differentiation. Our theory suggests that the effect of vertical differentiation on the trade elasticity works in the opposite direction in comparison to the effect of horizontal differentiation. ${ }^{17}$ The results reported in columns 3 and 4 confirm the expected direction by showing a negative effect of the interaction term for horizontal differentiation on trade, whereas the effect for vertical differentiation remains positive and significant. The same holds for the results on the share of firms, as reported in Table B6.

\footnotetext{
${ }^{17}$ As in Chaney (2008), the impact of trade costs on the extensive margin is larger for products with higher degree of horizontal differentiation (lower elasticity of substitution $\sigma_{j}$ ).
} 
Table 5: Robustness checks using R\&D intensity and horizontal differentiation: Results for aggregate trade flows

\begin{tabular}{rrrrr}
\hline Dependent variable: & & & & \\
$\ln S_{n i j}$ & $(1)$ & $(2)$ & $(3)$ & $(4)$ \\
$\ln$ Dist $n i$ & $-0.643^{* * *}$ & & $-0.512^{* * *}$ & \\
& $(0.0365)$ & & $(0.0406)$ & \\
$\ln$ Dist $_{n i} *$ R\&D & $0.0619^{* * *}$ & $0.0705^{* * *}$ & $0.0625^{* * *}$ & $0.0716^{* * *}$ \\
& $(0.00826)$ & $(0.00796)$ & $(0.00824)$ & $(0.00789)$ \\
$\ln$ Dist $_{n i} *$ GM index & & & $-0.262^{* * *}$ & $-0.312^{* * *}$ \\
& & & $(0.0473)$ & $(0.0466)$ \\
\hline Constant & yes & yes & yes & yes \\
$i j$ fixed effects & yes & yes & yes & yes \\
$n j$ fixed effects & yes & yes & yes & yes \\
$n i$ fixed effects & no & yes & no & yes \\
Observations & 88,789 & 88,789 & 88,789 & 88,789 \\
R-squared & 0.621 & 0.723 & 0.621 & 0.723 \\
\hline Notes: ${ }^{*}$ significant at 10\%; ${ }^{* *}$ significant at $5 \% ; * * *$ significant at $1 \%$. \\
The errors clustered by importer-exporter pair. \\
\hline
\end{tabular}

\subsubsection{Results controlling for product weights and income per capita}

The distance effect on trade could capture alternative mechanisms unrelated to our theoretical framework, such as demand and income effects associated with Alchian-Allen or home market effects related to the Linder (1961) hypothesis. In the robustness checks below we tackle these issues.

First, one important concern is that the results could capture a correlation between the degree of differentiation of the good and the relative weight of the product: products that are heavier with respect to their value are likely to travel shorter distances. Moreover, as shown by Alchian and Allen (1964), consumption shifts towards higher-quality products when products face per-unit costs. Hence, we can expect that products with higher value-perweight are shipped to longer distances. We exploit information on the unit codes of products and compute the log average export value per kilogram by industry $\left(\ln k g_{-} v_{n i j}\right)$. To achieve consistency across products, we only use information for the unit codes measured in weights (metric tons), which accounts for roughly $80 \%$ of the sample, and interact ln $k g_{-} v_{n i j}$ with distance. If our results for the distance elasticity are affected by relatively lighter products (in terms of value per kilogram) being able to reach longer destinations, the interaction term should be positive and should affect our distance coefficient. In the results for total sales $\left(\ln S_{n i j}\right)$ shown in Table B7 and for the share of exporters $\left(\gamma_{n j}\right)$ in Table B8, we control for the interaction term $\ln k g_{-} v_{n i j} * \ln d i s t$. The positive and significant coefficients 
for the interaction term reported in columns 1 and 4 in Table B7 mean that distance is less important for products with higher value per weight, which is consistent with the Alchian and Allen hypothesis. However, our coefficient of interest remains significant and with similar magnitudes when adding $\ln k g_{-} v_{n i j} * \ln$ dist as a control variable. This is true for both measures of vertical differentiation, ladder $_{j}$ and R\&D. ${ }^{18}$ Note that the level effect ln $k g_{-} v_{n i j}$ shown in Table B7 is negative once we add $i, n, j, i j$ and $n j$ fixed effects. Within an industry and for every $i j$ and $n j$, products with higher unit values are associated with lower trade volumes. The level effect is no longer negative if we do not account for these fixed effects, which are crucial to control for multilateral resistance terms. The results for the share of exporters reported in Table B8 are not significant, whereas our coefficient of interest remains stable and significant.

Second, our results could reflect systematic variation between the type of product traded and the income similarity of origin and destination. For instance, it could capture the fact that high-income countries trade more products of high quality because of home market effects, which implies that quality is an important determinant of the direction of trade (Linder, 1961). On the demand side, high-income countries spend a larger fraction of their income on high-quality goods. On the supply side, countries develop a comparative advantage according to local demand and tastes of consumers, and sell these products to other countries that share these tastes.

To account for income similarity, we investigate the sensitivity of the results when adding a "Linder term". We follow Hallak (2010) and construct a measure of dissimilarity of income between pairs of countries as follows: inder $_{n i}=\left(\ln C G D P_{i}-\ln C G D P_{n}\right)^{2}$, where $C G D P$ is the income per capita of a country. Following Hallak (2010), we expect that a larger Linder term Linder $_{n i}$ (i.e., more dissimilar incomes) leads to smaller trade flows. The Linder (1961) hypothesis is confirmed in Table B7 columns 2-3 and 5-6 for total sales and in Table B8 for the share of firms. There is a negative relation between income dissimilarity $\left(\right.$ Linder $\left._{n i}\right)$ and trade flows. This negative relation is even stronger for high-quality goods, as reported by the interaction terms $\operatorname{Linder}_{n i} * \operatorname{ladder}_{j}$ and $\operatorname{Linder}_{n i} *$ R\&D. For the share of firms, the results are not significant. However, also in this case, our coefficients of interest remain significant and with similar magnitudes, which lends support to our mechanism.

\footnotetext{
${ }^{18}$ The magnitudes are not directly comparable to the results reported in Table 1, since the number of observations is different from the baseline results. However, in results available upon request, we find similar magnitudes in the baseline estimations for the sample of products measured in weights (metric tons) used in Table B7. Moreover, the magnitudes of the interaction term should be interpreted with caution, as

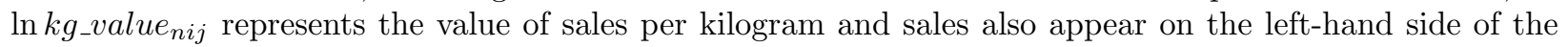
regression. Hence, measurement error may appear on both sides of the regression, generating a mechanical positive bias in the OLS estimate. Despite this caveat, the results suggest that our coefficient of interest remains stable.
} 


\subsubsection{The elasticity of trade flows with respect to variable costs: results using panel data}

The results from Tables 1 and 3 already show that quality does not affect the elasticity with respect to variable costs (proxied by tariffs). As an alternative to investigate proposition 3 regarding variable trade costs, we can also use panel data, which has the advantage that we can account for importer-exporter-industry fixed effects $\left(v_{n i j}\right)$. We estimate a time-varying gravity equation as follows:

$$
\ln S_{n i j t}=\beta_{1} \ln \tau_{n i j t}+\beta_{2} \ln \tau_{n i j t} * \ln \text { ladder }_{j}+v_{n i j}+\mu_{t}+\varepsilon_{n i j t},
$$

where $S_{n i j t}$ are bilateral trade flows in industry $j$ and year $t$. Because the effect of variable trade costs on exports depends only on the Pareto shape parameter (see proposition 3 and equation 25), the effect of $\tau_{n i j t}$ on $S_{n i j t}$ should be solely captured by $\beta_{1}$. The results are reported in Table B9 using MFN tariffs. Using panel data, we show that $\beta_{1}<0$ in all columns, in accordance with the baseline results. Moreover, the results in columns 3 and 4 confirm that $\beta_{2}$ is not significant.

\subsubsection{Zeros and trade: Results using poisson pseudo maximum likelihood}

A standard concern regarding the estimation of gravity equations using OLS is the presence of zero trade. To tackle this issue, we investigate the robustness of the main results using a poisson pseudo maximum likelihood (PPML) estimation. Because the data at the bilateral country and industry level imply many zero values, we conduct the analysis using a more aggregated industry classification.

For the analysis with the industry ladder, the estimation is conducted at the 2-digit industry level. In the case of the sample using $\mathrm{R} \& \mathrm{D}$ intensity, we use data at the 3-digit industry level, as the data is available for a smaller number of industries and also constains a smaller number of zeros. The results reported in Table B10 reveal that the coefficients remain robust. Accouting for zeros in trade, the coefficient of interest is even larger in magnitude in all specifications. ${ }^{19}$

\footnotetext{
${ }^{19}$ Also in this case, the coefficients are not directly comparable as the estimations are conducted at a different level of disaggregation. However, a replication of our baseline results using the data at a more aggregate level (2-digit and 3-digit level) reveals that the OLS results are smaller in magnitudes in comparison to the PPML estimations.
} 


\subsubsection{Additive trade costs}

In previous robustness checks, we have shown that the distance effect remains robust controlling for ad valorem tariffs as a proxy for variable trade costs. However, as shown by Irarrazabal et al. (2015), an important part of trade costs is additive rather than ad valorem, meaning that they are defined as a constant monetary cost per unit traded, rather than as a constant percentage of the producer price. Additive trade costs might affect our variable of interest, as they influence relative consumption patterns both within and across markets (see Alchian and Allen (1964)). A high quality product becomes cheaper relative to a low quality product in the presence of additive tariffs.

We use firm-level data to estimate additive trade costs $\left(A T C_{n j}\right)$ using a nonlinear least squares estimator as in Irarrazabal et al. (2015). They allow for the presence of additive trade costs besides the standard iceberg transportation costs $\left(\tau_{n i j}\right)$ and propose a framework to structurally estimate the magnitude of additive trade costs using firm-level data. The underlying mechanism relates higher additive trade costs with a less negative demand elasticity, and more so among low price firms. The estimation procedure is described in Appendix B.1. Table B11 reports our baseline estimations controlling for additive trade costs $A T C_{n j}$ as well as for the interaction term $A T C_{n j} *$ ladder $_{j}$ in columns 3 and 4 . Because the sample is much smaller, we also report the results without $A T C_{n j}$ in columns 1 and 2 of Table B11, to make the results comparable to the baseline results in Table 1. The results reveal that the effect of $A T C_{n j}$ on the share of firms is negative, meaning that higher additive trade costs are associated with less firm entry. Perhaps surprisingly, the interaction effect $A T C_{n j} * \operatorname{ladder}_{j}$ is also negative and significant. On the other hand, our coefficient of interest remains stable and is even slightly higher in magnitudes once we control for additive trade costs.

\subsubsection{Trade quantities}

Products of higher quality are traded at higher values. In previous robustness checks, we have shown that the results remain robust when we control for the value per weight of the product. As an alternative to account for a potential bias in trade flows, we investigate traded quantities instead of values. Table B12 shows that, for both quality measures ladder $_{j}$ and $\mathrm{R} \& \mathrm{D}$, the distance effect on trade quantities is lower in industries with higher scope for vertical differentiation. Hence, the results are not driven by the value per unit of the product. 


\section{$5 \quad$ Estimation of model}

The preceding analysis has shown that vertical differentiation reduces the distance effect on trade flows and the share of exporters. In this section, we analyze the quantitative effects of lower trade barriers across industries and compare it to a benchmark case without vertical differentiation. To do so, we need industry estimates for the following parameters of our model: the Pareto shape parameter $\xi_{j}$, the elasticity of substitution $\sigma_{j}$, and the technology ratio $\frac{1-\theta_{j}}{\alpha_{j}}$. We follow a three-step procedure to obtain the parameter values for each industry. First, we use the estimates for the Pareto shape parameter from Crozet and Koenig (2010). ${ }^{20}$ This step exploits that the elasticity of trade flows with respect to variable trade costs (25) is only determined by the Pareto shape parameter $\xi_{j}$. Second, we estimate the elasticity of exports with respect to distance (23), which is a function of all three parameters, controlling for multilateral resistance terms. Third, we exploit data on R\&D intensity from Kugler and Verhoogen (2012), which corresponds to the scope for vertical differentiation (18) in our theoretical setup. ${ }^{21}$

Table 6: Parameter estimates by industry

\begin{tabular}{lccc}
\hline Industry & $\xi_{j}$ & $\sigma_{j}$ & $\frac{1-\theta_{j}}{\alpha_{j}}$ \\
\hline Builder's carpentry and joinery & 1.65 & 1.88 & 0.011 \\
Newsprint & 3.71 & 3.23 & 0.012 \\
Printing paper and writing paper & 3.71 & 3.01 & 0.012 \\
Paper and paperboard & 3.71 & 2.98 & 0.012 \\
Packing containers, box files of paper & 3.71 & 2.77 & 0.008 \\
Paper pulp, paper, paperboard & 3.71 & 2.58 & 0.064 \\
Textile yarn, synthetic fibres, not for retail & 1.84 & 1.99 & 0.091 \\
Machinery, equipment for heating and cooling & 3.21 & 2.76 & 0.045 \\
Filtering, purifying machinery, for liquids, gases & 3.21 & 2.82 & 0.045 \\
Parts of purifying and filtering machinery & 3.21 & 2.77 & 0.045 \\
Valves for pipes boiler shells & 3.21 & 2.77 & 0.027 \\
Shaft, crank, bearing housing, pulley & 3.21 & 2.74 & 0.052 \\
Precious jewellery & 1.92 & 2.24 & 0.089 \\
Sound recording tape, discs & 1.92 & 2.07 & 0.070 \\
Orthophaedic appliances, hearing aids & 1.92 & 2.08 & 0.098 \\
\hline
\end{tabular}

Table 6 reports estimates for 4-digit industries which are among the 15 largest in terms

\footnotetext{
${ }^{20}$ Crozet and Koenig (2010) estimate the model of Chaney (2008) using French firm-level data. Note that in our model the elasticity of trade flows with respect to variable trade costs does not depend on the degree of vertical differentiation and is the same as in Chaney (2008).

${ }^{21}$ Note that this procedure does not allow to estimate the technology parameters separately, but only the ratio $\frac{1-\theta_{j}}{\alpha_{j}}$. This, however, is sufficient to calculate the effects of lower trade barriers as shown in equations (23) and (24).
} 
of sales within their 2-digit classification. The estimates for further industries are avaiable in our Web Appendix. We use these estimates to simulate a $10 \%$ decrease in fixed trade costs. Figure 1 shows the effects on export flows by industry. The strongest reaction can be observed for paper (exports increase by 11\%), whereas the smallest positive effect occurs for precious jewellery (about 4\%).

Figure 1: Effects of trade liberalization on exports by industry (in \%)

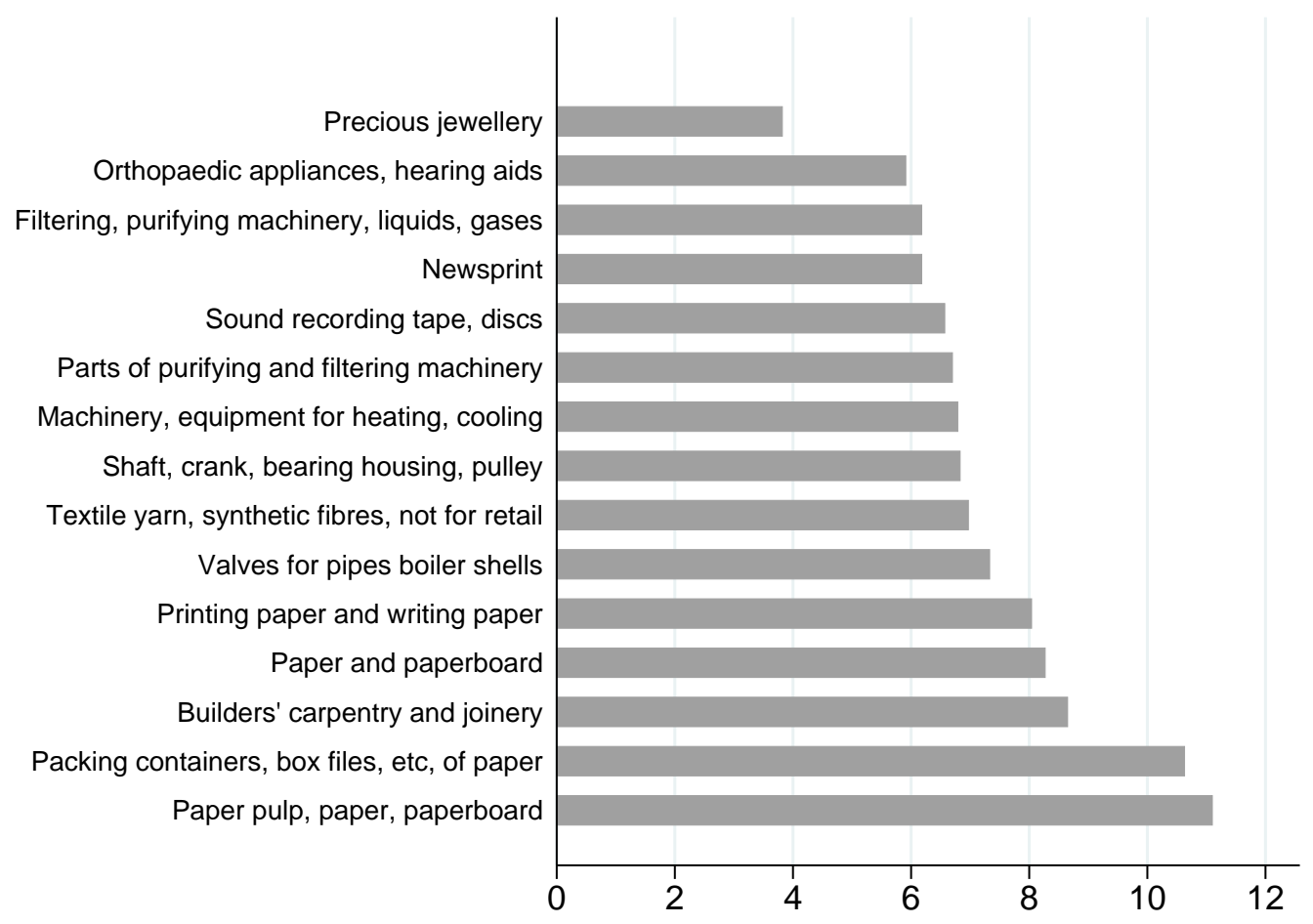

In a next step, we compare the trade effects to a benchmark model without vertical differentiation. As discussed in subsection 2.4, the impact of lower trade barriers can be divided into a direct Chaney (2008)-effect and a new quality effect. For our benchmark case, we shut down the latter channel and compute the elasticity of trade flows and the extensive margin without quality differentiation. Intuitively, the quality channel would disappear, whenever technology parameters $\theta_{j}$ and $\alpha_{j}$ are sufficiently high. In this case, returns from quality investments are rather low and vertical differentiation has a negligible effect on the margins of international trade.

Figure 2 depicts the relative effects of lower trade barriers compared to the benchmark scenario without vertical differentiation, whereas the grey bars show the effect for total trade flows and the black bars the reaction at the extensive margin. Compared to standard 
Figure 2: Effects of trade liberalization on exports relative to benchmark scenario

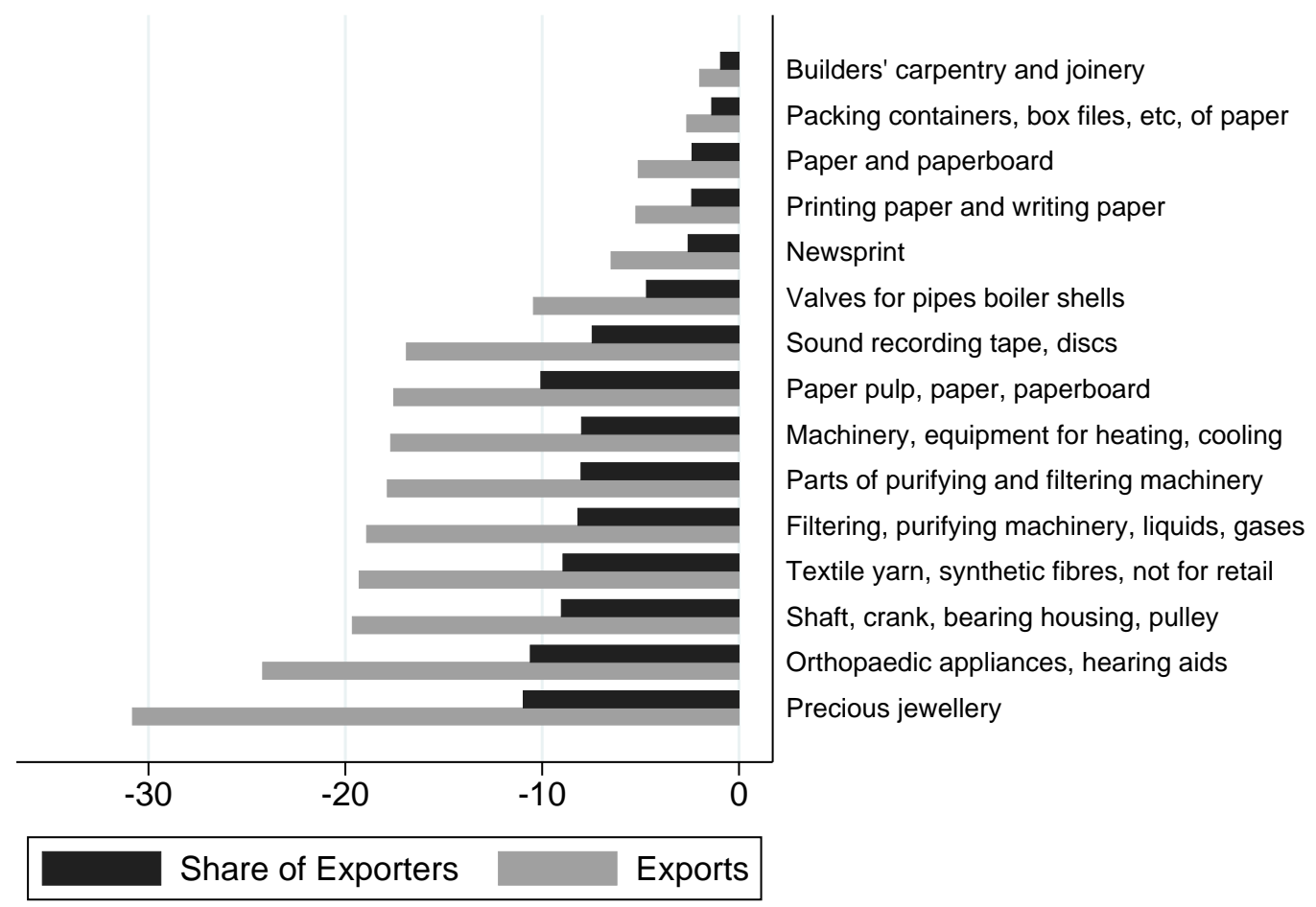

models without quality differentiation, our model suggests smaller effects of lower trade barriers across all industries. Export flows by industry are on average by $14 \%$ lower, whereas the reaction on the extensive margin is by $6 \%$ lower. Figure 2 further shows that the relative effects are very heterogeneous across industries. Whereas industries with a low degree of vertical differentiation show only a small deviation from the benchmark model, trade effects become substantially lower in industries with high quality products. In particular, for precious jewellery the positive effect on exports is reduced by more than $30 \%$ compared to a model without vertical differentiation.

Welfare effects The relative trade effects as shown in Figure 2 are very similar to the welfare implications compared with the benchmark case without vertical differentiation. To analyze the welfare effects of lower fixed trade costs, we use the inverse of the industry price 
index (4) as welfare measure: ${ }^{22}$

$$
W_{j}=P_{j}^{-1}=\Omega_{i i j}\left(\beta_{j} L_{i}\right)^{\frac{1}{\sigma_{j}-1}} \varphi_{i i j}^{*}
$$

whereas $\Omega_{i i j}=\left(1-\theta_{j}\right)^{\frac{1-\theta_{j}}{\alpha_{j}}}\left(\frac{\sigma_{j}-1}{\sigma_{j}}\right)^{\frac{1+\alpha_{j}-\theta_{j}}{\alpha_{j}}}\left(\frac{\alpha_{j}-\left(1-\theta_{j}\right)\left(\sigma_{j}-1\right)}{\alpha_{j} \sigma_{j} f_{i i}}\right)^{\frac{\alpha_{j}-\left(\sigma_{j}-1\right)\left(1-\theta_{j}\right)}{\alpha_{j}\left(\sigma_{j}-1\right)}}$ and the entry cutoff productivity $\varphi_{i i j}^{*}$ is defined in equation (15). The effect of fixed trade costs on welfare is thus given by:

$$
\frac{d \ln W_{j}}{d \ln f_{n i}}=\left(\frac{1}{\xi_{j}}-\frac{1}{\sigma_{j}-1}+\frac{1-\theta_{j}}{\alpha_{j}}\right) \lambda_{n i j}
$$

whereas $\lambda_{n i j}$ is the trade share of goods from industry $j$ and country $i$ to destination $n$ :

$$
\lambda_{n i j}=\frac{S_{n i j}}{S_{i j}}=\frac{\left(\frac{f_{n i}}{f_{i i}}\right)^{-\xi_{j} \frac{\alpha_{j}-\left(\sigma_{j}-1\right)\left(1-\theta_{j}\right)}{\alpha_{j}\left(\sigma_{j}-1\right)}} f_{n i} \tau_{n i}^{-\xi_{j}}}{\sum_{n}\left(\frac{f_{n i}}{f_{i i}}\right)^{-\xi_{j} \frac{\alpha_{j}-\left(\sigma_{j}-1\right)\left(1-\theta_{j}\right)}{\alpha_{j}\left(\sigma_{j}-1\right)}} f_{n i} \tau_{n i}^{-\xi_{j}}}
$$

The elasticity shown in equation (30) reveals that welfare effects are lower in industries with a high scope for vertical differentiation. A comparison with the elasticity shown in equation (23) makes clear that vertical differentiation influences relative welfare responses in a very similar way as trade flows. In industries with high quality differentiation, a reduction in fixed costs or trade barriers has only a limited impact on firm entry and thus welfare gains are low. Hence, the analysis shows that our model predicts lower gains from trade compared to gravity models that build on Chaney (2008) and Melitz (2003), and more importantly the gains are more heterogeneous. This is especially true in industries with a high degree of vertical differentiation and large firm heterogeneity.

\section{Conclusion}

This paper highlights, both theoretically and empirically, that the elasticity of trade with respect to fixed costs is lower in industries with a higher degree of vertical product differentiation. We introduce quality innovations with endogenous sunk costs in a heterogenous firm model of international trade and derive the gravity equation. Our model predicts that export flows and the share of exporters are less sensitive to fixed costs in more vertically differentiated industries. Based on our theoretical setup, we estimate gravity equations for

\footnotetext{
${ }^{22}$ Note that overall welfare is given by the upper-tier utility function in equation (1) and is a weighted sum of the industry consumption levels. As we are interested in the gains from trade by industry, we focus on the inverse price index.
} 
aggregate bilateral data and Brazilian firm-level data. We account for industrial variation in vertical differentiation by using the "quality ladder" suggested by Khandelwal (2010) and industry-level R\&D intensity.

We find strong support for our hypothesis that vertical differentiation interacts with fixed costs in the gravity equation, using different proxies for fixed costs. Instead, the interaction of quality and variable trade costs is insignificant, as suggested by our model. We estimate the parameters of our model and simulate the effect of lower fixed trade barriers. Our model predicts that gains from trade are lower and become more heterogeneous across industries compared to a benchmark model without vertical differentiation.

Consistent with our theory, we show that the effect of vertical differentiation affects trade through the extensive margin, which points to the importance of endogenous sunk costs. In vertically differentiated industries, investment conditions are more favorable and thus incentives to innovate are high. This holds in particular for high productivity firms with large sales, which increases competition. Hence, small and low productivity firms can only reap tiny market shares, which reduces the impact of trade liberalization on the extensive margin and thus on aggregate export flows.

This paper aims to contribute to the literature on quality and gravity in international trade. The analysis suggests that accounting for vertical differentiation is important for understanding the geography of international trade, as well as for the evaluation of trade liberalizing policies. 


\section{References}

Alchian, A. A. and W. R. Allen (1964). University Economics. Wadsworth.

Antoniades, A. (2015). Heterogeneous Firms, Quality, and Trade. Journal of International Economics 95(2), 263-273.

Arkolakis, C., S. Ganapati, and M.-A. Muendler (2016). The extensive margin of exporting products: A firm-level analysis. Cowles Foundation Discussion Paper 2028.

Baldwin, R. and J. Harrigan (2011). Zeros, Quality, and Space: Trade Theory and Trade Evidence. American Economic Journal: Microeconomics 3(2), 60-88.

Bastos, P. and J. Silva (2010). The quality of a firm's exports: Where you export to matters. Journal of International Economics 82(2), 99-111.

Breinlich, H., S. Dhingra, and G. Berlingieri (2016). The impact of trade agreements on consumer welfare. CEPR DP11148.

Bustos, P. (2011). Trade liberalization, exports, and technology upgrading: Evidence on the impact of mercosur on argentinian firms. American Economic Review 11, 304-340.

Chaney, T. (2008). Distorted Gravity: The Intensive and Extensive Margins of International Trade. American Economic Review 98(4), 1707-21.

Crozet, M., K. Head, and T. Mayer (2012). Quality sorting and trade: Firm-level evidence for french wine. The Review of Economic Studies 79(2), 609-644.

Crozet, M. and P. Koenig (2010, February). Structural gravity equations with intensive and extensive margins. Canadian Journal of Economics 43(1), 41-62.

Faber, B. (2014). Trade liberalization, the price of quality, and inequality: Evidence from mexican store prices. Working paper, UC Berkely.

Fajgelbaum, P. D., G. M. Grossman, and E. Helpman (2011). Income distribution, product quality, and international trade. Journal of Political Economy 119, 721-765.

Feenstra, R. C., R. E. Lipsey, H. Deng, A. C. Ma, and H. Mo (2005, January). World Trade Flows: 1962-2000. NBER Working Papers 11040, National Bureau of Economic Research, Inc.

Feenstra, R. C. and J. Romalis (2014). International Prices and Endogenous Quality. The Quarterly Journal of Economics 129(2), 477-527. 
Ferguson, S. (2012). Cross-Industry Heterogeneity in Export Participation: The Role of Scale Economies in R\&D. Working Paper Series 930, Research Institute of Industrial Economics.

Flach, L. (2016). Quality upgrading and price heterogeneity: Evidence from brazilian exporters. Journal of International Economics 102, 282-290.

Gollop, F. M. and J. L. Monahan (1991). A generalized index of diversification: Trends in u.s. manufacturing. Review of Economics and Statistics 73, 318-330.

Hallak, J. C. (2010). A Product-Quality View of the Linder Hypothesis. The Review of Economics and Statistics 92(3), 453-466.

Irarrazabal, A., A. Moxnes, and L. Opromolla (2015). The tip of the iceberg: A quantitative framework for estimating trade costs. The Review of Economics and Statistics 97(4), $777-792$.

Johnson, R. C. (2012). Trade and prices with heterogeneous firms. Journal of International Economics 86(1), 43-56.

Khandelwal, A. (2010). The Long and Short (of) Quality Ladders. Review of Economic Studies $77(4), 1450-1476$.

Kugler, M. and E. Verhoogen (2012). Prices, Plant Size, and Product Quality. Review of Economic Studies 79(1), 307-339.

Linder, S. B. (1961). An essay on trade and transformation. Almqvist \& Wiksell Stockholm.

Manova, K. and Z. Zhang (2012). Export Prices Across Firms and Destinations. The Quarterly Journal of Economics 127(1), 379-436.

Martin, J. (2012). Markups, quality, and transport costs. European Economic Review 56, $777-791$.

Martin, J. and F. Mayneris (2015). High-end variety exporters defying gravity: Micro facts and aggregate implications. Journal of International Economics 96(1), 55-71.

Melitz, M. J. (2003). The Impact of Trade on Intra-Industry Reallocations and Aggregate Industry Productivity. Econometrica 71 (6), 1695-1725.

Melitz, M. J. and S. J. Redding (2014). Heterogeneous Firms and Trade, Volume 4, Chapter 1, pp. 1-54. Elsevier. 
Sutton, J. (2007). Quality, Trade and the Moving Window: The Globalisation Process. Economic Journal 117(524), F469-F498.

Sutton, J. (2012). Competing in Capabilities: The Globalization Process. Oxford University Press.

Verhoogen, E. A. (2008). Trade, Quality Upgrading, and Wage Inequality in the Mexican Manufacturing Sector. The Quarterly Journal of Economics 123(2), 489-530.

World Bank (2016). Doing Business. Trading Across Borders. Washington, DC, World Bank Group. 


\section{A Mathematical Appendix}

\section{A.1 Firm maximization problem}

A firm in industry $j$ and country $i$ maximizes profits (7) and takes into account consumer's demand (3), whereas sales in destination $n$ are defined as: $s_{n i j}=p_{n i j} x_{n i j}$. The first-order conditions with respect to the optimal price $p_{n i j}$ and quality choice $q_{n i j}$ are given by:

$$
\begin{gathered}
\frac{\partial \pi_{n i j}}{\partial p_{n i j}}=A_{n j} q_{n i j}^{\sigma_{j}-1}\left[\left(1-\sigma_{j}\right) p_{n i j}^{-\sigma_{j}}+\tau_{n i} \sigma_{j} p_{n i j}^{-\sigma_{j}-1} \frac{q_{n i j}^{\theta_{j}}}{\varphi}\right]=0, \\
\frac{\partial \pi_{n i j}}{\partial q_{n i j}}=A_{n j} p_{n i j}^{-\sigma_{j}} q_{n i j}^{\sigma_{j}-2}\left[\left(\sigma_{j}-1\right) p_{n i j}-\tau_{n i} \frac{\theta_{j}+\sigma_{j}-1}{\varphi} q_{n i j}^{\theta_{j}}\right]-q_{n i j}^{\alpha_{j}-1}=0 .
\end{gathered}
$$

The optimal price (8) follows immediately from condition (32). Inserting equation (8) into the second condition (32) and simplifying yields to the optimal quality level (9).

\section{A.2 Derivation of entry cutoff productivity}

To derive the entry cutoff productivity (15), we combine the zero-profit condition (12) with the free-entry condition (14). Sales (10) of a firm in industry $j$ in country $i$ from serving market $n$ can be expressed relative to the cutoff productivity $\varphi_{n i j}^{*}$ :

$$
s_{n i j}(\varphi)=\frac{\alpha_{j} \sigma_{j} f_{n i}}{\alpha_{j}-\left(1-\theta_{j}\right)\left(\sigma_{j}-1\right)}\left(\frac{\varphi}{\varphi_{n i j}^{*}}\right)^{\frac{\alpha_{j}\left(\sigma_{j}-1\right)}{\alpha_{j}-\left(\sigma_{j}-1\right)\left(1-\theta_{j}\right)}} .
$$

Inserting expression (34) into the free-entry condition (14) leads to:

$$
\sum_{n}\left[\left(1-G_{i j}\left(\varphi_{n i j}^{*}\right)\right)\right] f_{n i}\left[\left(\frac{\widetilde{\varphi}_{n i j}}{\varphi_{n i j}^{*}}\right)^{\frac{\alpha_{j}\left(\sigma_{j}-1\right)}{\alpha_{j}-\left(\sigma_{j}-1\right)\left(1-\theta_{j}\right)}}-1\right]=f_{E i},
$$

whereas the following definition of average productivity is used:

$$
\widetilde{\varphi}_{n i j}=\left[\frac{1}{1-G_{i j}\left(\varphi_{n i j}^{*}\right)} \int_{\varphi_{n i j}^{*}}^{\infty} \varphi^{\frac{\alpha_{j}\left(\sigma_{j}-1\right)}{\alpha_{j}-\left(\sigma_{j}-1\right)\left(1-\theta_{j}\right)}} g_{i}(\varphi) d \varphi\right]^{\frac{\alpha_{j}-\left(\sigma_{j}-1\right)\left(1-\theta_{j}\right)}{\alpha_{j}\left(\sigma_{j}-1\right)}} .
$$

As described in section 2.4, we assume that productivity is Pareto distributed with density function $g_{i j}(\varphi)=\xi_{j} \varphi^{-\xi_{j}-1}$, whereas $\xi$ is the Pareto shape parameter. This implies that the 
probability of serving market $n$, can be written as: $1-G_{i j}\left(\varphi_{n i j}^{*}\right)=\left(\varphi_{n i j}^{*}\right)^{-\xi_{j}}$, which allows to rewrite the free-entry condition (35):

$$
\sum_{n} f_{n i}\left(\varphi_{n i j}^{*}\right)^{-\xi_{j}}=\frac{\xi_{j}\left[\alpha_{j}-\left(\sigma_{j}-1\right)\left(1-\theta_{j}\right)\right]-\alpha_{j}\left(\sigma_{j}-1\right)}{\alpha_{j}\left(\sigma_{j}-1\right)} f_{E i} .
$$

In a last step, we exploit that the cutoff productivity of serving a particular destination $n$ relative to the entry cutoff productivity in the domestic market is a function of fixed and variable trade costs:

$$
\frac{\varphi_{n i j}^{*}}{\varphi_{i i j}^{*}}=\tau_{n i}\left(\frac{f_{n i}}{f_{n n}}\right)^{\frac{\alpha_{j}-\left(\sigma_{j}-1\right)\left(1-\theta_{j}\right)}{\alpha_{j}\left(\sigma_{j}-1\right)}} .
$$

Combining equations (37) and (38) leads to the expression for the entry cutoff productivity (15) in the main text.

\section{A.3 Gravity equation}

This part derives the gravity equation as presented in section 2.4. We insert the expression for sales (10) into equation (19) and use the definition of average productivity (36), which leads to:

$$
S_{n i j}=\frac{1-G_{i j}\left(\varphi_{n i j}^{*}\right)}{1-G_{i j}\left(\varphi_{i i j}^{*}\right)} M_{i j}\left(\frac{Y_{n j} \widetilde{\varphi}_{n i j}^{\sigma-1}}{P_{n j}^{1-\sigma_{j}}}\right)^{\frac{\alpha_{j}}{\alpha_{j}-\left(\sigma_{j}-1\right)\left(1-\theta_{j}\right)}} \Theta^{\frac{\sigma_{j}-1}{\alpha_{j}-\left(\sigma_{j}-1\right)\left(1-\theta_{j}\right)}}
$$

whereas $\Theta=\left(1-\theta_{j}\right)^{1-\theta_{j}}\left(\frac{\sigma_{j}}{\sigma_{j}-1}\right)^{\theta_{j}-1-\alpha_{j}} \tau_{n i}^{-\alpha_{j}}$. The assumption that productivity is Pareto distributed (compare Appendix A.2), implies that: $\frac{1-G_{i j}\left(\varphi_{n i j}^{*}\right)}{1-G_{i j}\left(\varphi_{i i j}^{*}\right)}=\left(\frac{\varphi_{n i j}^{*}}{\varphi_{i i j}^{*}}\right)^{-\xi_{j}}$. Furthermore, average productivity can be expressed relative to the cutoff productivity $\varphi_{n i j}^{*}$ :

$$
\left(\frac{\widetilde{\varphi}_{n i j}}{\varphi_{n i j}^{*}}\right)^{\frac{\alpha_{j}\left(\sigma_{j}-1\right)}{\alpha_{j}-\left(\sigma_{j}-1\right)\left(1-\theta_{j}\right)}}=\frac{\xi_{j}\left[\alpha_{j}-\left(\sigma_{j}-1\right)\left(1-\theta_{j}\right)\right]}{\xi_{j}\left[\alpha_{j}-\left(\sigma_{j}-1\right)\left(1-\theta_{j}\right)\right]-\alpha_{j}\left(\sigma_{j}-1\right)} .
$$

We insert these two relationships together with expression (13) into equation (39), which yields:

$$
S_{n i j}=\underbrace{\left(\frac{\varphi_{i i j}^{*}}{\varphi_{n i j}^{*}}\right)^{\xi_{j}} M_{i j} \frac{\xi_{j} \alpha_{j} \sigma_{j} f_{n i}}{\xi_{j}\left[\alpha_{j}-\left(\sigma_{j}-1\right)\left(1-\theta_{j}\right)\right]-\alpha_{j}\left(\sigma_{j}-1\right)}}_{\text {Extensive margin }} .
$$

In a last step, we exploit the relationship in equation (38) to arrive at equation (21). 


\section{A.4 Vertical differentiation and the "quality ladder"}

This part shows that the degree of vertical differentiation in equation (18) is closely linked to the "quality ladder" by Khandelwal (2010), which we use in the empirical analysis. To see this, we consider a log-linearized version of firm sales (10) as a function of the quality-price ratio (16):

$$
\ln s_{n i j}(\varphi)=\ln A_{n j}+\left(\sigma_{j}-1\right) \frac{\ln q_{n i j}}{\ln p_{n i j}},
$$

whereas the log-linearized quality-price ratio is given by:

$$
\frac{\ln q_{n i j}}{\ln p_{n i j}}=\frac{\left(1-\theta_{j}\right)\left[\ln \left(1-\theta_{j}\right)+\ln A_{n j}\right]+\left(\theta_{j}-1-\alpha_{j}\right) \ln \left(\frac{\sigma_{j}}{\sigma_{j}-1}\right)+\alpha_{j}\left(\ln \varphi-\ln \tau_{n i j}\right)}{\alpha_{j}-\left(\sigma_{j}-1\right)\left(1-\theta_{j}\right)} .
$$

Combining equations (42) and (43) leads to the following expression for firm sales:

$$
\ln s_{n i j}(\varphi)=\frac{\alpha_{j} \ln A_{n j}+\left(\sigma_{j}-1\right)\left(\Delta_{j}+\alpha_{j} \ln \varphi-\alpha_{j} \ln \tau_{n j}\right)}{\alpha_{j}-\left(\sigma_{j}-1\right)\left(1-\theta_{j}\right)},
$$

whereas $A_{n j}$ represents destination-industry fixed effects, and $\Delta_{j}=\left(1-\theta_{j}\right) \ln \left(1-\theta_{j}\right)-$ $\left(\alpha_{j}+1-\theta_{j}\right) \ln \left(\frac{\sigma_{j}}{\sigma_{j}-1}\right)$ captures industry characteristics. Conditional on these effects, the positive relationship between firm sales and productivity $\varphi$ increases in the degree of vertical differentiation, as the slope of the sales curve $\frac{\alpha_{j}\left(\sigma_{j}-1\right)}{\alpha_{j}-\left(\sigma_{j}-1\right)\left(1-\theta_{j}\right)}$ decreases in $\alpha_{j}$. Intuitively, a higher degree of vertical differentiation leads to a larger market share after controlling for exporter productivity, as well as industry- and destination characteristics. Hence, the degree of vertical differentiation and the "quality ladder" by Khandelwal (2010) are closely related, as both measures capture the quality component in the demand function. Note that this argument holds also for the estimation of market shares as in Khandelwal (2010).

\section{B Empirical Appendix}

\section{B.1 Data and descriptive statistics}

\section{Firm-level data from SECEX (Foreign Trade Secretariat)}

We use firm-level data for Brazilian manufacturing exporters collected by the Foreign Trade Secretariat to compute the share of exporters by industry and destination. The data contains export values and export quantities by firm, 8-digit product, and destination country. Firms in the SECEX data are identified by the unique CNPJ tax number and products are coded according to the 8-digit NCM Mercosur classification of goods (NCM-SH Nomenclatura 
Comum do Mercosul, Sistema Harmonizado). The first 6 digits coincide with the 6-digit HS classification, which allows a direct mapping between product-level data and the 4-digit SITC classification (Standard International Trade Classification).

Since we are only interested in manufacturing exporters, we exclude observations related to agriculture and the mining sector, as well as commercial intermediates. Hence, we consider only the sample of products which refer to machinery, metals, stone/glass, plastics/rubbers, footwear, textiles, wood products, and leather products. If the observation contains zero exporting value, it was removed from the sample. As described in Arkolakis et al. (2016), these observations correspond to reporting errors or shipments of commercial samples. As in Arkolakis et al. (2016), 484 observations are removed.

The main reason for using the year 2000 is data availability, as 2000 is the last year for which there is information on world trade flows from NBER-UN coded by Feenstra et al. (2005).

Doing Business - Trading Across Borders (World Bank, 2016).

We use data from Doing Business by the World Bank to create bilateral measures of fixed costs associated with the administrative costs to ship goods, which is constructed as the sum of importer trade time/cost and exporter trade time/cost for a bilateral pair.

The first measure refers to the time for importer and exporter documentary compliance $\left(t_{-} d o c_{n i}\right)$, which includes the time in hours to comply with the documentary requirements of the government agencies in the origin and destination country, including transit economies. The measure includes the time and cost for obtaining documents, preparing documents (such as time spent to prepare customs declaration or certificate of origin), processing documents (for instance, time spent waiting for a phytosanitary certificate to be issued), presenting documents, and submitting documents (such as the time spent submitting customs declaration, in person or electronically).

An alternative measure is the time for border compliance $\left(t_{-} b o r d_{n i}\right)$, which includes the time in hours to comply with the regulations relating to customs clearance and mandatory inspections to cross the border. The measure includes the time and cost for obtaining, preparing and submitting documents during port or border handling, customs clearance and inspection procedures. The time for border compliance also includes inspections by agencies other than customs (if applied to more than $10 \%$ of shipments). For instance, inspections related to health, safety and phytonsanitary standards. The data is obtained for the most widely used port or border of the country.

Note that the measures from the Doing Business - Trading across borders are not bilateral. However, since they are divided into the cost to import and to export of every country, we create for the importer-exporter pair a bilateral measure, which refers to the sum of 
time-to-ship goods measured in hours.

The data indicates a statistically significant correlation at the $1 \%$ level between distance and the measures of compliance from the World Bank, as reported in Table B1.

Summary statistics for the main variables used in the baseline estimations are shown in Table B2.

Table B1: Correlation between distance and compliance measures

\begin{tabular}{rcc}
\hline Correlation & $\ln t_{-}$border \\
ni & $\ln t_{-} d o c_{n i}$ \\
\hline $\ln$ Dist $_{n i}$ & $0.2366^{* * *}$ & $0.3816^{* * *}$ \\
\hline
\end{tabular}

Table B2: Summary statistics

\begin{tabular}{|c|c|c|c|}
\hline Variable & Obs & Mean & Std. Dev. \\
\hline \multicolumn{4}{|c|}{ Sample using bilateral world trade data, year 2000} \\
\hline $\ln S_{n i j}$ & 159,039 & 6.953 & 1.764 \\
\hline $\ln$ Dist $_{n i}$ & 159,039 & 8.459 & 1.01 \\
\hline $\operatorname{ladder}_{j}$ & 159,039 & 1.903 & 0.697 \\
\hline$\tau_{n i j}$ & 159,039 & 0.063 & 0.08 \\
\hline $\ln t_{-} d o c_{n i}$ & 409,443 & 2.73 & 1.717 \\
\hline $\ln t_{-} b o r d e r_{n i}$ & 357,769 & 3.758 & 1.417 \\
\hline Language $_{n i}$ & 422,843 & 0.153 & 0.360 \\
\hline$R \& D$ intensity & 88,789 & 0.031 & 0.022 \\
\hline Gollop Monahan (GM) index & 88,789 & 0.492 & 0.137 \\
\hline \multicolumn{4}{|c|}{ Sample using firm-level data, year 2000} \\
\hline Share of firms $\gamma_{n j}$ & 60,029 & 0.126 & 0.113 \\
\hline $\ln$ Dist $_{n}$ & 60,029 & 8.603 & 0.751 \\
\hline $\operatorname{ladder}_{j}$ & 60,029 & 1.756 & 0.625 \\
\hline $\ln t_{-}$border $_{n}$ & 43,802 & 3.835 & 1.368 \\
\hline $\ln t_{-} d o c_{n}$ & 42,647 & 3.047 & 1.841 \\
\hline$R \& D$ intensity & 14,333 & 0.028 & 0.016 \\
\hline GollopMonahan index & 14,333 & 0.51 & 0.103 \\
\hline
\end{tabular}

\section{Estimation of additive trade costs}

An important part of trade costs is additive rather than ad valorem (Irarrazabal et al., 2015), meaning that part of the costs are defined as a constant monetary cost per unit traded, rather than as a constant percentage of the producer price (ad valorem). We follow Irarrazabal et al. (2015) and use firm-level data to estimate additive trade costs $\left(A T C_{n i}\right)$ using a nonlinear least squares estimator. For that, we only need export unit values at the firm-product-destination level.

Irarrazabal et al. (2015) allow for the presence of additive trade costs besides the standard iceberg transportation costs $\left(\tau_{n i}\right)$ and propose a framework to structurally estimate the magnitude of additive trade costs using firm-level data. The underlying mechanism relates higher additive trade costs with a less negative demand elasticity, and more so among low 
price firms. Although consumer prices are unobserved, information on free on board export prices can be used for the empirical analysis. Hence, from a standard framework with CES preferences, Irarrazabal et al. (2015) derive the following estimating equation:

$$
\ln x_{n i j}=\tilde{a}_{n j}-\sigma_{j} \ln \left(\tilde{p}_{n i j}+\tilde{t}_{n j}\right)+\epsilon_{n i j}
$$

where $\tilde{t}_{n j}=\frac{t_{n j}}{\tau_{n j}}$ and $\tilde{a}_{n j}=a_{n j}+\sigma_{j} \ln \tau_{n j} . \quad \tilde{p}_{n i j}$ are the free on board prices for a firm $i$ exporting product $j$ to country $n, a_{n j}$ is a standard demand shifter, $\tau_{n j}$ represents the standard multiplicative trade costs, and $t_{n j}$ are the additive trade costs. ${ }^{23}$

$\tilde{t}_{n j}$ can be further decomposed into product- and destination-specific fixed effects, $\tilde{t}_{n j}=\tilde{t}_{n} \tilde{t}_{j}$. This decomposition allows to separately identify trade costs that are due to product and market characteristics. Hence, the quantitative analysis exploits the relationship between f.o.b. price and export quantity across firms within a product-destination pair.

Using this framework and firm-level data with information on prices by product and destination, we can minimize the sum of the squared residuals. To limit the number of fixed effects, we follow Irarrazabal et al. (2015) and restrict the sample to product-destinations that are exported by many firms. In the context of the Brazilian data, we keep products that are sold by at least 50 firms and 30 destination countries. We drop extreme unit values below the 1st percentile or above the 99 th percentile for every product-destination. ${ }^{24}$

Finally, with the estimates of $\tilde{t}_{n}$ and $\tilde{t}_{j}$, we calculate trade costs relative to the median f.o.b. prices by $n j$, such that $A T C_{n j}=\frac{\tilde{t}_{n j}}{\tilde{p}_{n j}}$, which is the measure used in the empirical analysis. Table B3 provides summary statistics.

Table B3:
\begin{tabular}{lccc}
\hline Variable & Obs & Mean & Std. Dev. \\
\hline$A T C_{n j}$ & 8,050 & 0.021 & 0.016 \\
\hline
\end{tabular}

\footnotetext{
${ }^{23}$ Note that the model allows firms to vary quality of a given product across destination markets, which is important in our framework. Quality differences across markets would be captured by the constant term $\tilde{a}_{n j}$.

${ }^{24}$ One concern with this procedure could be selection bias, as firms do not randomly enter into different product-destinations, which can create a correlation between prices and the error term. However, as Irarrazabal et al. (2015) argue, this selection effect would only affect the slope parameters, and not the estimates of trade costs.
} 


\section{B.2 The distance coefficient by industry: Results for aggregate trade flows and the share of firms}

To provide a better visualization of the results for the distance coefficient shown in Tables 1 and 3, we aggregate the data to the 2-digit industry level and run the following regression with industry-specific coefficients:

$$
\ln S_{n i j}=\beta_{1} \text { fixedcosts }_{n i}+\sum_{j=1}^{J} \beta_{j} \text { ladder }_{j} * \text { fixedcost }_{n i}+\tau_{n i j}+\rho_{i j}+\mu_{n j}+\varepsilon_{n i j},
$$

where $\operatorname{ladder}_{j}$ is the industry-specific quality ladder and $\beta_{j}$ are the industry-specific coefficients. We expect that, controlling for the level effect $\left(\right.$ fixedcosts $_{n i}$ ) and for average tariffs $\left(\tau_{n i j}\right)$, higher quality ladders are associated with a more positive $\beta_{j}$. We conduct the same analysis for the share of firms.

The interaction terms by industry $\left(\sum_{j=1}^{J} \beta_{j}\right.$ ladder $_{j} *$ fixedcost $\left._{n i}\right)$ are reported in Figure B1 for total trade (left panel) and the share of firms (right panel). As expected, more positive coefficients are associated with a higher ladder. Note that, because we aggregate the data taking means by 2-digit industry level in Figure B1, the quality ladder varies less than in our empirical analysis. Whereas the 2-digit log ladder ranges from zero to one, the 4-digit log ladder used in the empirical analysis ranges from -2.32 to 1.56 .

Figure B1: Correlation between vertical differentiation and the estimated distance coefficient by industry, for share of firms (left) and total sales (right)
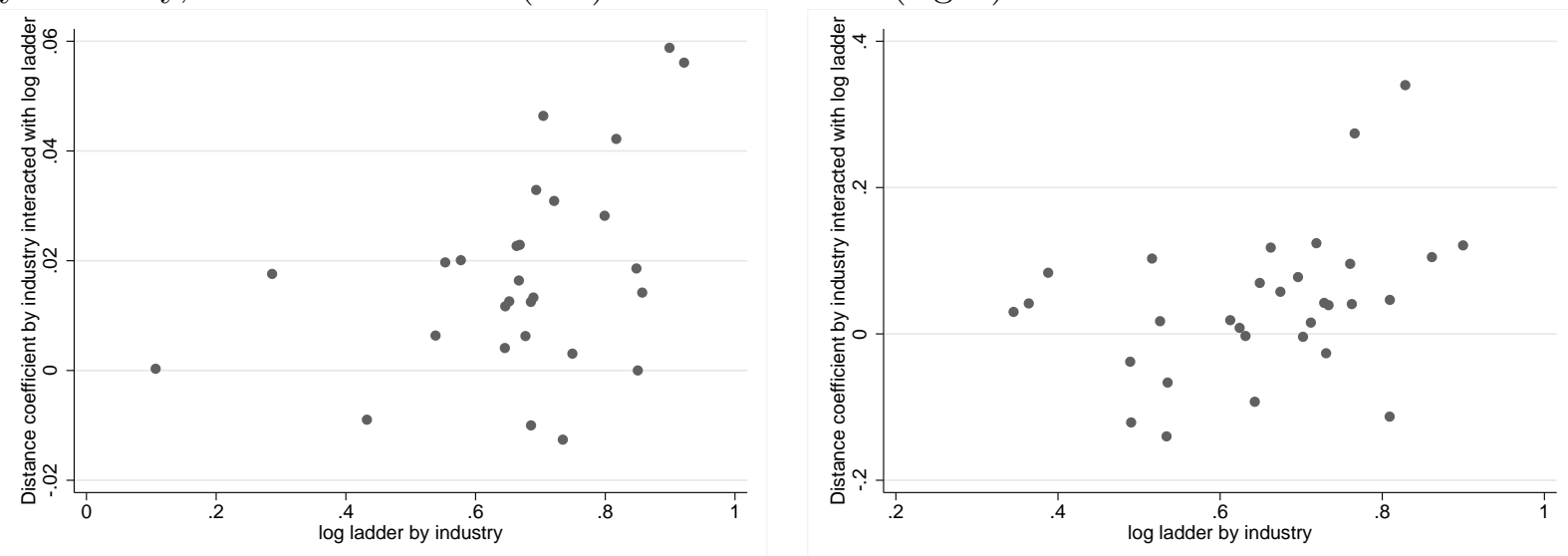


\section{B.3 Robustness checks}

Because there are many missing values in the tariff data, the results from Table 1 are reported for a more restricted sample to allow a comparison of the coefficients across columns. In Table B4 we report the results for the interaction term ln Dist $_{n i} *_{\text {ladder }_{j}}$ using the complete sample without tariff data. The results remain stable and robust. Moreover, in Table B4 columns 4 to 7 we conduct a robustness check using MFN tariffs instead of AHS tariffs as a control variable. The results for the distance coefficient remain stable and significant.

Summary statistics for the full sample are reported in Table B5.

Table B4: Fixed costs and aggregate trade flows: Results using the full sample and $\ln \tau_{n i j}$ MFN as alternative

\begin{tabular}{|c|c|c|c|c|c|c|c|}
\hline $\begin{array}{l}\text { Dependent variable } \\
\qquad \ln S_{n i j}\end{array}$ & $(1)$ & $(2)$ & $(3)$ & (4) & $(5)$ & $(6)$ & (7) \\
\hline $\ln$ Dist $_{n i}$ & $\begin{array}{c}-0.856^{* * *} \\
(0.0188)\end{array}$ & $\begin{array}{c}-0.938^{* * *} \\
(0.0221)\end{array}$ & & $\begin{array}{c}-0.959^{* * *} \\
(0.0285)\end{array}$ & & $\begin{array}{c}-0.959^{* * *} \\
(0.0285)\end{array}$ & \\
\hline $\ln D_{i s t} t_{n i} * \operatorname{ladder}_{j}$ & & $\begin{array}{c}0.0431^{* * *} \\
(0.00447)\end{array}$ & $\begin{array}{c}0.0496^{* * *} \\
(0.00425)\end{array}$ & $\begin{array}{c}0.100^{* * *} \\
(0.0122)\end{array}$ & $\begin{array}{c}0.105^{* * *} \\
(0.0122)\end{array}$ & $\begin{array}{c}0.100^{* * *} \\
(0.0122)\end{array}$ & $\begin{array}{c}0.105^{* * *} \\
(0.0122)\end{array}$ \\
\hline $\ln \tau_{n i j} \mathrm{MFN}$ & & & & $\begin{array}{c}-0.550^{* *} \\
(0.220)\end{array}$ & $\begin{array}{c}-0.679^{* * *} \\
(0.206)\end{array}$ & $\begin{array}{c}-0.814^{* *} \\
(0.337)\end{array}$ & $\begin{array}{c}-0.710^{* *} \\
(0.339)\end{array}$ \\
\hline $\operatorname{ladder}_{j} * \ln \tau_{n i j} \mathrm{MFN}$ & & & & & & $\begin{array}{c}0.511 \\
(0.518)\end{array}$ & $\begin{array}{l}0.0603 \\
(0.554)\end{array}$ \\
\hline Constant & yes & yes & yes & yes & yes & yes & yes \\
\hline$n j$ fixed effects & yes & yes & yes & yes & yes & yes & yes \\
\hline$i j$ fixed effects & yes & yes & yes & yes & yes & yes & yes \\
\hline$n i$ fixed effects & no & no & yes & no & yes & no & yes \\
\hline Observations & 420,849 & 420,849 & 420,849 & 159,039 & 159,039 & 159,039 & 159,039 \\
\hline R-squared & 0.626 & 0.626 & 0.707 & 0.656 & 0.720 & 0.656 & 0.720 \\
\hline
\end{tabular}

Notes: ${ }^{*}$ significant at $10 \% ; * *$ significant at $5 \% ; * * *$ significant at $1 \%$.

The errors are clustered by importer-exporter pair.

Table B5: Summary statistics - full sample

\begin{tabular}{lccc}
\hline Variable & Obs & Mean & Std. Dev. \\
\hline $\ln S_{n i j}$ & 420,849 & 6.903 & 1.744 \\
$\ln$ Dist $_{n i}$ & 420,849 & 8.132 & 1.103 \\
ladder $_{j}$ & 420,849 & 1.904 & 0.701 \\
\hline
\end{tabular}


Table B6: Robustness checks using R\&D intensity and horizontal differentiation: Results for the share of firms

\begin{tabular}{rrrrr}
\hline Dependent variable: & & & & \\
$\gamma_{n j}$ & $(1)$ & $(2)$ & $(3)$ & \multicolumn{1}{c}{$(4)$} \\
\hline $\ln$ Dist $_{n}$ & -0.00387 & $0.0324^{* *}$ & & \\
& $(0.0119)$ & $(0.0130)$ & & \\
$\ln$ Dist $_{n} * R \& D_{j}$ & $0.0118^{* * *}$ & $0.0109^{* * *}$ & $0.0131^{* * *}$ & $0.0122^{* * *}$ \\
& $(0.00330)$ & $(0.00314)$ & $(0.00325)$ & $(0.00309)$ \\
$\ln$ Dist $_{n} *$ GM Index & & $-0.0779^{* * *}$ & & $-0.0724^{* * *}$ \\
& & $(0.0133)$ & & $(0.0134)$ \\
\hline Constant & yes & yes & yes & yes \\
$n$ fixed effects & no & no & yes & yes \\
$j$ fixed effects & yes & yes & yes & yes \\
Observations & 13,990 & 13,990 & 13,990 & 13,990 \\
R-squared & 0.472 & 0.473 & 0.510 & 0.510 \\
\hline
\end{tabular}

Notes: ${ }^{*}$ significant at $10 \%$; ${ }^{* *}$ significant at $5 \%$; ${ }^{* * *}$ significant at $1 \%$.

The errors are clustered by importer $n$. 
Table B7: Robustness checks for the value per weight: Results for aggregate trade flows

Dependent variable

\begin{tabular}{|c|c|c|c|c|c|c|}
\hline $\ln S_{n i j}$ & (1) & $(2)$ & $(3)$ & (4) & $(5)$ & (6) \\
\hline $\ln$ Dist $_{n i} *$ ladder $_{j}$ & $\begin{array}{c}0.0561^{* * *} \\
(0.00783)\end{array}$ & $\begin{array}{c}0.0679^{* * *} \\
(0.00723)\end{array}$ & $\begin{array}{c}0.0783^{* * *} \\
(0.00668)\end{array}$ & & & \\
\hline $\ln D_{i s t_{n i}} * R \& D_{j}$ & & & & $\begin{array}{c}0.0479^{* * *} \\
(0.00926)\end{array}$ & $\begin{array}{c}0.0627^{* * *} \\
(0.00834)\end{array}$ & $\begin{array}{c}0.0735^{* * *} \\
(0.00811)\end{array}$ \\
\hline $\ln D i s t * \ln k g \_v a l u e_{n i j}$ & $\begin{array}{c}0.0459^{* * *} \\
(0.00324)\end{array}$ & & & $\begin{array}{c}0.0215^{* * *} \\
(0.00520)\end{array}$ & & \\
\hline $\ln k g \_v a l u e_{n i j}$ & $\begin{array}{c}-0.323^{* * *} \\
(0.0269)\end{array}$ & & & $\begin{array}{c}-0.158^{* * *} \\
(0.0427)\end{array}$ & & \\
\hline Linder $_{n i}$ & & $\begin{array}{c}-0.0169^{* *} \\
(0.00746)\end{array}$ & & & $\begin{array}{c}-0.0302^{*} \\
(0.0168)\end{array}$ & \\
\hline Linder $_{n i} *$ ladder $_{j}$ & & $\begin{array}{c}-0.0270^{* * *} \\
(0.00333)\end{array}$ & $\begin{array}{c}-0.0327^{* * *} \\
(0.00312)\end{array}$ & & & \\
\hline $\ln D_{i s t} i$ & & $\begin{array}{c}-0.887^{* * *} \\
(0.0204)\end{array}$ & & & $\begin{array}{c}-0.628^{* * *} \\
(0.0371)\end{array}$ & \\
\hline $\operatorname{Linder}_{n i} * R \& D_{j}$ & & & & & $\begin{array}{c}0.000199 \\
(0.00377)\end{array}$ & $\begin{array}{c}-0.00867^{* *} \\
(0.00398)\end{array}$ \\
\hline Constant & yes & yes & yes & yes & yes & yes \\
\hline$j$ fixed effects & yes & yes & yes & yes & yes & yes \\
\hline$n$ fixed effects & yes & yes & yes & yes & yes & yes \\
\hline$i$ fixed effects & yes & yes & yes & yes & yes & yes \\
\hline$n j$ fixed effects & yes & yes & yes & yes & yes & yes \\
\hline$i j$ fixed effects & yes & yes & yes & yes & yes & yes \\
\hline$n i$ fixed effects & yes & no & yes & yes & no & yes \\
\hline Observations & 317,546 & 419,455 & 417,836 & 67,557 & 89,817 & 88,176 \\
\hline R-squared & 0.720 & 0.628 & 0.708 & 0.732 & 0.620 & 0.723 \\
\hline
\end{tabular}

Notes: ${ }^{*}$ significant at $10 \%$; $*$ significant at $5 \%$; *** significant at $1 \%$.

The errors are clustered by importer-exporter pair. 
Table B8: Robustness checks for income and value per weight: Results for the share of firms

\begin{tabular}{|c|c|c|c|c|}
\hline \multicolumn{5}{|l|}{ Dependent variable } \\
\hline$\gamma_{n j}$ & (1) & (2) & (3) & (4) \\
\hline $\ln$ Dist $_{n} *$ ladder $_{j}$ & $\begin{array}{c}0.0125^{* * *} \\
(0.00228)\end{array}$ & & $\begin{array}{c}0.0132^{* * *} \\
(0.00211)\end{array}$ & \\
\hline $\ln D_{i s t_{n}} * R \& D_{j}$ & & $\begin{array}{c}0.0124^{* * *} \\
(0.00356)\end{array}$ & & $\begin{array}{c}0.00962^{* *} \\
(0.00405)\end{array}$ \\
\hline $\ln D_{i s t_{n}} * \ln k g_{-}$value $_{n i j}$ & $\begin{array}{c}7.95 \mathrm{e}-05 \\
(5.63 \mathrm{e}-05)\end{array}$ & $\begin{array}{c}4.67 \mathrm{e}-05 \\
(0.000121)\end{array}$ & & \\
\hline Linder $_{n i} *$ ladder $_{j}$ & & & $\begin{array}{l}0.000181 \\
(0.00114)\end{array}$ & \\
\hline $\operatorname{Linder}_{n i} * R \& D_{j}$ & & & & $\begin{array}{c}0.00162 \\
(0.00130)\end{array}$ \\
\hline Constant & yes & yes & yes & yes \\
\hline$n$ fixed effects & yes & yes & yes & yes \\
\hline$j$ fixed effects & yes & yes & yes & yes \\
\hline Observations & 55,845 & 13,095 & 55,945 & 12,619 \\
\hline R-squared & 0.484 & 0.477 & 0.494 & 0.471 \\
\hline
\end{tabular}

Table B9: Variable trade costs and aggregate trade flows

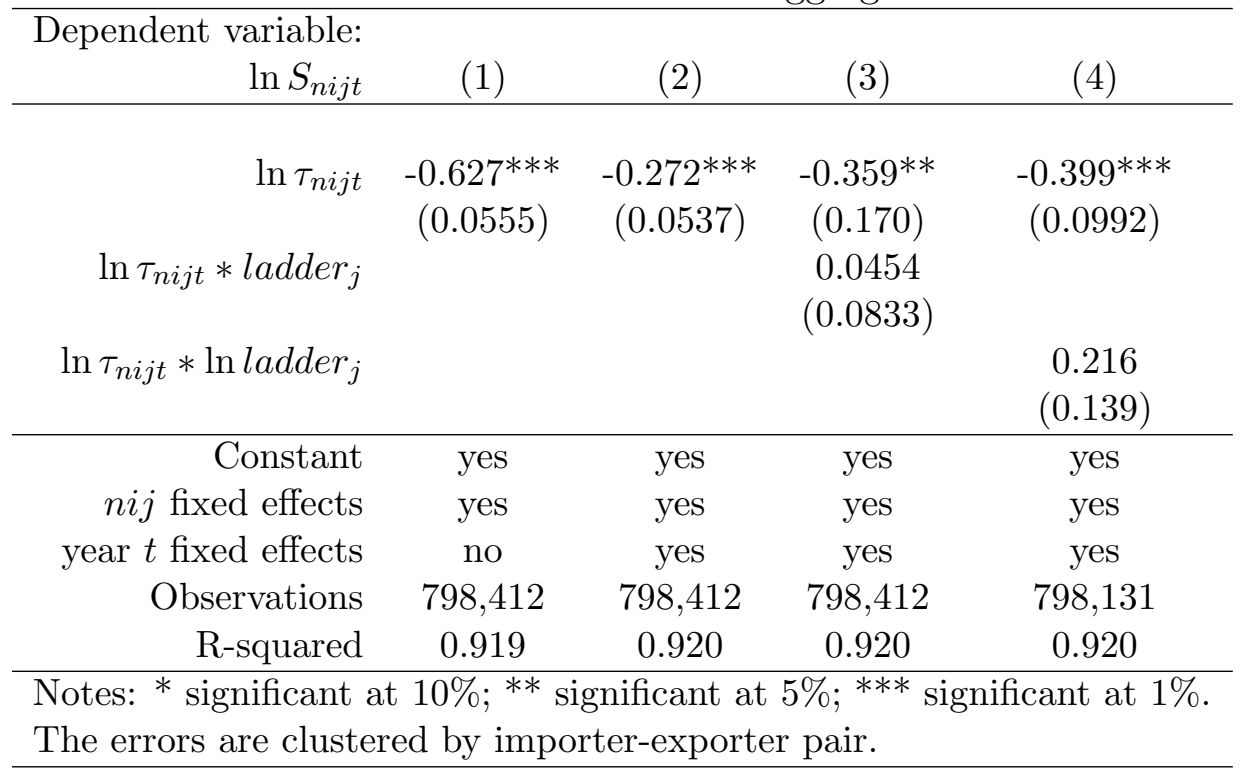


Table B10: Zeros and trade: Estimations with PPML

\begin{tabular}{|c|c|c|c|c|}
\hline $\begin{array}{r}\text { Dependent variable } \\
S_{n i j}\end{array}$ & (1) & $(2)$ & (3) & (4) \\
\hline $\ln$ Dist $_{n i}$ & $\begin{array}{c}-0.501^{* * *} \\
(0.109)\end{array}$ & $\begin{array}{c}-0.365^{* * *} \\
(0.117)\end{array}$ & $\begin{array}{c}-0.841^{* * *} \\
(0.0427)\end{array}$ & $\begin{array}{c}-0.874^{* * *} \\
(0.0500)\end{array}$ \\
\hline $\ln D_{i s t_{n i}} * R \& D_{j}$ & $\begin{array}{c}0.0724^{* *} \\
(0.0297)\end{array}$ & $\begin{array}{c}0.0711^{* *} \\
(0.0292)\end{array}$ & & \\
\hline $\ln D_{i s t_{n i}}^{*} \mathrm{GM}$ Index & & $\begin{array}{l}-0.280 \\
(0.193)\end{array}$ & & \\
\hline $\ln D_{i s t_{n i}} * \ln \operatorname{ladder}_{j}$ & & & $\begin{array}{l}0.0639^{*} \\
(0.0341)\end{array}$ & \\
\hline $\ln \operatorname{Dist}_{n i} *$ ladder $_{j}$ & & & & $\begin{array}{c}0.0383^{* *} \\
(0.0163)\end{array}$ \\
\hline Constant & yes & yes & yes & yes \\
\hline$j$ fixed effects & yes & yes & yes & yes \\
\hline$n$ fixed effects & yes & yes & yes & yes \\
\hline$i$ fixed effects & yes & yes & yes & yes \\
\hline Observations & 243,575 & 243,575 & 231,827 & 231,829 \\
\hline
\end{tabular}

Table B11: Robustness checks for additive trade costs: Results for the share of firms Dependent variable

\begin{tabular}{|c|c|c|c|c|}
\hline$\gamma_{n j}$ & (1) & $(2)$ & $(3)$ & (4) \\
\hline \multirow[t]{2}{*}{$\ln$ Dist $_{n} *$ ladder $_{j}$} & $0.0138^{*}$ & $0.0145^{*}$ & $0.0142^{*}$ & $0.0147^{* *}$ \\
\hline & $(0.00746)$ & $(0.00742)$ & (0.00739) & $(0.00739)$ \\
\hline \multirow{2}{*}{$\ln$ Dist $_{n}$} & $-0.109 * * *$ & & $-0.121^{* * *}$ & \\
\hline & $(0.0148)$ & & $(0.0149)$ & \\
\hline \multirow{2}{*}{$A T C_{n j}$} & & & $-0.0226^{* * *}$ & $-0.0224^{* *}$ \\
\hline & & & $(0.00821)$ & $(0.00975)$ \\
\hline \multirow[t]{2}{*}{$A T C_{n j} *$ ladder $_{j}$} & & & & $-0.00170^{*}$ \\
\hline & & & & $(0.000953)$ \\
\hline Constant & yes & yes & yes & yes \\
\hline$j$ fixed effects & yes & yes & yes & yes \\
\hline$n$ fixed effects & no & yes & no & yes \\
\hline Observations & 8,050 & 8,050 & 8,050 & 8,050 \\
\hline R-squared & 0.404 & 0.450 & 0.413 & 0.451 \\
\hline
\end{tabular}

Notes: ${ }^{*}$ significant at $10 \% ;{ }^{* *}$ significant at $5 \% ; * * *$ significant at $1 \%$. The errors are clustered by importer $n$. 
Table B12: Fixed costs and trade quantities

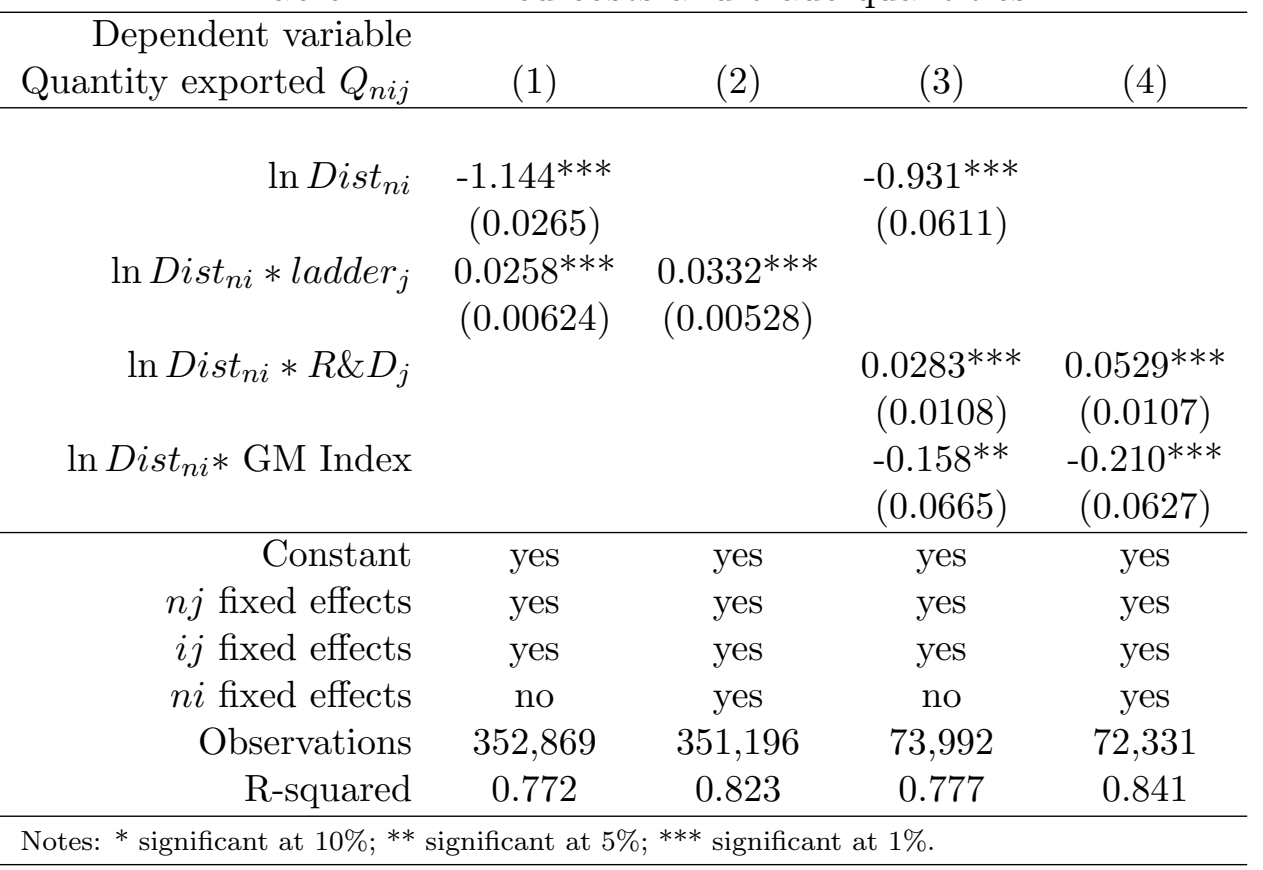

